FEDERAL RESERVE BANK OF SAN FRANCISCO

WORKING PAPER SERIES

\title{
Speculative Growth, Overreaction, and the Welfare Cost of Technology-Driven Bubbles
}

\author{
Kevin J. Lansing \\ Federal Reserve Bank of San Francisco \\ and Norges Bank
}

February 2012

Working Paper 2008-08

http://www.frbsf.org/publications/economics/papers/20008/wp08-08bk.pdf

The views in this paper are solely the responsibility of the author and should not be interpreted as reflecting the views of the Federal Reserve Bank of San Francisco or the Board of Governors of the Federal Reserve System. 


\title{
Speculative Growth, Overreaction, and the Welfare Cost of Technology-Driven Bubbles*
}

\author{
Kevin J. Lansing ${ }^{\dagger}$ \\ Federal Reserve Bank of San Francisco and Norges Bank
}

February 13, 2012

\begin{abstract}
This paper develops a general equilibrium model to examine the quantitative effects of speculative bubbles on capital accumulation, growth, and welfare. A near-rational bubble component in the model equity price generates excess volatility in response to observed technology shocks. In simulations, intermittent equity price run-ups coincide with positive innovations in technology, investment and consumption booms, and faster trend growth, reminiscent of the U.S. economy during the late 1920s and late 1990s. The welfare cost of speculative bubbles depends crucially on parameter values. Bubbles can improve welfare if risk aversion is low and agents underinvest relative to the socially-optimal level. But for higher levels of risk aversion, the welfare cost of bubbles is large, typically exceeding one percent of annual consumption.
\end{abstract}

Keywords: Excess Volatility, Asset Pricing, Speculative Bubbles, Endogenous Growth, Welfare Cost of Business Cycles.

JEL Classification: E32, E44, G12, O40.

\footnotetext{
*Forthcoming, Journal of Economic Behavior and Organization. An earlier version of this paper was titled "Speculative Growth and Overeaction to Technology Shocks." For helpful comments and suggestions, I would like to thank the editors of this special issue, an anonymous referee, Gadi Barlevy, Ester Faia, Bill Gavin, Steve LeRoy, Raf Wouters, seminar participants at Norges Bank, the University of Delaware, Michigan State University, the 2010 Erasmus University Conference on Expectations, Bubbles, and Financial Crises, the 2009 AEA meeting, the 2009 North American Summer Meeting of the Econometric Society, the 2009 BIS/ECB Worskhop on Financial Fragility, the 2009 Chicago/London Conference on Financial Markets, the 2009 UC Riverside Conference on Business Cycles, the 2009 European Economics Association Meeting, the 2008 Meeting of the Society for Nonlinear Dynamics and Econometrics, and the 2008 Meeting of the Society for Computational Economics.

$\dagger$ Research Department, Federal Reserve Bank of San Francisco, P.O. Box 7702, San Francisco, CA 94120-7702, (415) 974-2393, FAX: (415) 977-4031, email: kevin.j.lansing@sf.frb.org, homepage: www.frbsf.org/economics/economists/klansing.html
} 
Bubbles are often precipitated by perceptions of real improvements in the productivity and underlying profitability of the corporate economy. But as history attests, investors then too often exaggerate the extent of the improvement in economic fundamentals.

Federal Reserve Chairman Alan Greenspan, August 30, 2002.

\section{Introduction}

\subsection{Overview}

The magnitude of short-term movements in stock prices remains a challenge to explain within a framework of rational, efficient markets. Numerous empirical studies starting with Shiller (1981) and LeRoy and Porter (1981) have shown that stock prices appear to exhibit "excess volatility" when compared to the discounted stream of ex post realized dividends. ${ }^{1}$ Another prominent feature of stock price data is the intermittent occurrence of sustained run-ups above estimates of fundamental value, so-called speculative bubbles, that can be found throughout history in various countries and asset markets. ${ }^{2}$ The dramatic rise in U.S. stock prices during the late 1990s, followed similarly by U.S. house prices during the mid 2000s, are episodes that have both been described as bubbles. The former episode was accompanied by a boom in business investment, while the later was accompanied by a boom in residential investment. Both booms were later followed by falling asset prices and severe retrenchments in the associated investment series, as agents sought to unwind the excess capital accumulated during the bubble periods. Coincident booms in stock prices and investment also occurred during the late 1920's - a period that shares many characteristics with the late 1990s. In particular, both periods witnessed major technological innovations that contributed to investor enthusiasm about a "new era." 3

This paper develops a general equilibrium model to examine the quantitative effects of speculative bubbles on capital accumulation, growth, and welfare. The framework for the analysis is a real business cycle model with endogenous growth and capital adjustment costs (an AK-type model) along the lines of Barlevy (2004). ${ }^{4}$ A near-rational bubble component in the model equity price generates excess volatility in response to observed technology shocks. I also allow for the possibility of an Arrow-Romer type productive externality, such that agents may underinvest relative to the socially-optimal level. The severity of the underinvestment

\footnotetext{
${ }^{1}$ Lansing and LeRoy (2012) provide a recent update on this literature.

${ }^{2}$ For an overview of historical bubble episodes, see the collection of papers in Hunter, Kaufman, and Pomerleano (2003).

${ }^{3}$ Similarities between the two periods are noted by Shiller (2000), Gordon (2006), and White (2006), as described further below.

${ }^{4}$ In support of this class of models, Ramey and Ramey (1995) find empirical evidence of a link between fluctuations and growth. McGrattan (1998) finds that periods of high investment rates roughly coincide with periods of high growth, as predicted by $A K$-type endogenous growth models.
} 
problem turns out to be important for analyzing the welfare consequences of fluctuations stemming from either speculative bubbles or business cycles which, in this model, can affect the economy's trend growth rate.

Labor supply in the model is inelastic, consistent with the idea that asset prices are determined in securities markets by agents who remain fully-employed at all times. ${ }^{5}$ The representative agent (a capitalist-entrepreneur) must only decide the fraction of available output to be devoted to investment, with the remaining fraction devoted to consumption. The investmentconsumption ratio pins down the value of the equity price-dividend ratio. In the fully-rational model, the technology response coefficient in the agent's decision rule is small in magnitude such that price-dividend ratio is nearly constant for reasonable levels of risk aversion. In contrast, the price-dividend ratio in long-run U.S. stock market data is volatile and highly persistent - close to a random walk. The model result obtains because rational agents understand that technology shocks give rise to both income and substitution effects which work in opposite directions. The two effects exactly cancel when the intertemporal elasticity of substitution in consumption (the inverse of the coefficient of relative risk aversion) is unity, representing logarithmic utility. In this case, the technology response coefficient in the rational agent's decision rule is zero, such that the resulting price-dividend ratio is constant.

To introduce excess volatility, I decompose the model equity price into a fundamental component and a bubble component. I postulate a law of motion for the bubble component that satisfies the associated no-arbitrage condition exactly at the model steady state (when technology shocks are zero) and approximately satisfies the no-arbitrage condition away from the steady state (when technology shocks are non-zero). The law of motion for the bubble component is characterized by a single parameter that governs the bubble's response to observed technology shocks. I calibrate the technology response parameter to match the volatility of the price-dividend ratio in long-run U.S. data. But for any value of this parameter, the bubble law of motion is "near rational" in the sense that there is little opportunity for arbitrage.

Unlike a rational bubble solution, the near-rational law of motion is stationary (but highly persistent) and allows the equity price to occasionally dip below the fundamental value in the bubble-free economy. The bubble component in the equity price maps directly into a bubble component of investment. The bubble-component of investment augments the stock of physical capital, but the shareholders who supply the investment funds receive no claim to any extra dividends; their expected return on the additional funds derives solely from the prospect for price appreciation of their shares. This is reminiscent of late-1990s investors who purchased shares in numerous initial public offerings of internet technology companiesfirms whose prospects for future earnings, let alone dividends, were basically nil. ${ }^{6}$ In a given

\footnotetext{
${ }^{5}$ The setup is also consistent with the near-zero elasticity estimates obtained by most empirical studies. For an overview of the empirical estimates, see Blundell and McCurdy (1999).

${ }^{6}$ The term "bubble" was coined in England in 1720 following the famous price run-up and crash of shares in the South Sea Company. The run-up led to widespread public enthusiasm for the stock market and an explosion
} 
period, the bubble component of investment influences the stochastic discount factor (via the consumption decision) and the total resources which are available to pay dividends to shareholders. Consequently, there is feedback from the bubble component to the fundamental equity price. In the presence of the bubble, the fundamental component of the equity price continues to exactly satisfy the agent's intertemporal consumption Euler equation.

In model simulations, intermittent equity price run-ups coincide with positive innovations in technology, investment and consumption booms, and faster trend growth, reminiscent of the U.S. economy during the late 1920s and late 1990s. The model can also generate prolonged periods where the price-dividend ratio remains in the vicinity of the rational model value. So long as technology shocks remain small, the bubble component in the equity price remains close to zero. Due to the nonlinear nature of the model solution, the simulated price-dividend ratio in the bubble model exhibits non-Gaussian features such as positive skewness and excess kurtosis. These features are also present in the data.

Interestingly, the bubble component also improves the model's ability to match the relative volatilities of consumption growth, investment growth, and output growth. Because of capital adjustment costs, investment growth in the rational model exhibits about the same volatility as output growth, whereas investment growth in the data is about three times more volatile than output growth. Barlevy (2004, p. 983) acknowledges the difficulty of generating sufficient investment volatility in a rational model with capital adjustment costs. In the bubble model, excess volatility of the equity price maps directly into excess volatility of investment, thereby improving the comparison with investment volatility in the data.

Finally, I examine the welfare costs of fluctuations that can be attributed to either: (i) speculative bubbles, or (ii) business cycles. Welfare costs are measured by the percentage change in per-period consumption that makes the agent indifferent between the two economies being compared. The welfare cost of bubbles depends crucially on parameter values. Bubbles can improve welfare (relative to the rational model) if risk aversion is low and agents underinvest relative to the socially-optimal level. But for higher levels of risk aversion, the welfare cost of bubbles is large, typically exceeding one percent of annual consumption. In dollar terms, one percent of annual U.S. consumption translates into a yearly cost of around $\$ 855$ per household in 2009 .

The welfare results are driven by the interaction of several effects. Since the bubble model directs more resources to investment on average, bubbles can help address the economy's underinvestment problem if one exists. But if the private marginal product of capital is equal to the social marginal product, then the bubble model is characterized by overinvestment which serves to reduce welfare. The bubble model is also characterized by higher volatility in investment which leads to inefficiency in the production of new capital due to the presence of

of highly-suspect companies attempting to sell shares to investors. As documented by Mackay (1841), one such venture notoriously advertised itself as "a company for carrying out an undertaking of great advantage, but nobody to know what it is." 
convex capital adjustment costs. As a mitigating factor, the bubble model's excess volatility in investment serves to lower the volatility of consumption growth relative to the rational model. Which of these effects dominate depends on parameter values. When risk aversion is low and the underinvestment problem is severe, bubbles can improve welfare, but the reverse holds true for higher levels of risk aversion or when underinvestment is less severe.

An important unsettled question in economics is whether policymakers should take deliberate steps to prevent or deflate asset price bubbles. ${ }^{7}$ Those who advocate leaning against bubbles point out that excessive asset prices can distort economic and financial decisions, creating costly misallocations that can take years to dissipate. Others argue that policies intended to prick a suspected bubble might send the economy into a recession, thereby foregoing the benefits of the boom that might otherwise continue. While the welfare results presented here do not settle the policy question, they do show that speculative bubbles can be very costly for typical parameter settings.

\subsection{Related Literature}

The term "excess volatility" implies that asset prices move too much to be explained by changes in dividends or cash flows. The behavioral finance literature has examined a wide variety of evidence pertaining to this phenomenon. Controlled experiments on human subjects suggest that people's decisions are influenced by various "heuristics," as documented by Tversky and Kahneman (1974). The "representativeness heuristic" is a form of non-Bayesian updating whereby subjects tend to overweight recent observations relative to the underlying laws of probability that govern the stochastic process. De Bondt and Thaler (1985) find evidence of overreaction in comparing returns of portfolios comprised of prior winning and losing stocks. Arbarbanell and Bernard (1992) and Easterwood and Nutt (1999) find evidence that security analysts' earnings forecasts tend to overreact to new information, particularly when the information is positive in nature. Daniel, et al. (1998) develop a model where investors' overconfidence about the precision of certain types of information causes them to overreact to that information. In the laboratory asset market of Caginalp et al. (2000), prices appeared to overreact to fundamentals and to be driven by previous price changes, i.e., momentum.

This paper also relates to a line of research that explores the links between non-fundamental asset price movements and investment in physical capital. Theoretical research that examines rational bubbles in overlapping generations models with productive externalities or market imperfections includes Saint Paul (1992), Grossman and Yanagawa (1993), King and Ferguson (1993), Oliver (2000), and Caballero et al. (2006). This paper goes beyond previous work by exploring the quantitative implications of bubbles in a plausibly-calibrated model.

The capital adjustment cost formulation in the model implies that movements in the equity price are linked directly to movements in investment, as in a standard Tobin's $q$ framework.

\footnotetext{
${ }^{7}$ For an overview of the various arguments, see Lansing $(2008,2011)$.
} 
Along these lines, an empirical study by Barro (1990) finds that changes in real stock prices since 1891 have strong explanatory power for the growth rate of business investment. Studies by Chirinko and Schaller (2001), Gilchrist et al. (2005), and Campello and Graham (2012) all find evidence of a significant empirical link between stock price bubbles and investment decisions by firms.

Dupor (2005) examines the policy implications of non-fundamental asset price movements in monetary business cycle model with capital adjustments costs. Non-fundamental asset price movements are driven by exogenous "expectation shocks" that a drive a wedge between the true marginal product of capital and the market return observed by firms when making their investment decisions. The volatility of these shocks is calibrated to match a return volatility statistic for the S\&P 500 index, analogous to the procedure used here to calibrate the law of motion for the bubble component of the equity price. He finds that optimal monetary policy should lean against non-fundamental asset price movements. Hassan and Mertens (2011) consider the welfare costs of excess volatility in a capitalist-worker model where the forecasts of capital owners are perturbed away from the rational expectation by an exogenous shock, similar to the model of Dupor (2005).

\section{Historical Motivation}

A reading of stock market history suggests that speculative bubbles are often linked to technological innovation. Shiller (2000) argues that major stock price run-ups have generally coincided with the emergence of some superficially plausible "new era" theory that involves the introduction of new technology. Figure 1 depicts four major run-ups in real U.S. stock prices. ${ }^{8}$ Shiller associates each run-up with the following technological advances that contributed to new era enthusiasm:

- Early 1900s: High-speed rail travel, transatlantic radio, long-line electrical transmission.

- 1920s: Mass production of automobiles, travel by highways and roads, commercial radio broadcasts, widespread electrification of manufacturing.

- 1950s and 60s: Widespread introduction of television, advent of the suburban lifestyle, space travel.

- Late 1990s: Widespread availability of the internet, innovations in computers and information technology, emergence of the web-based business model.

In comparing the late 1920s with the late 1990s, Gordon (2006) and White (2006) both emphasize the simultaneous occurrence of major technological innovations, a productivity

\footnotetext{
${ }^{8}$ The series for real stock prices, real dividends, and real per capita consumption employed in the paper are from Robert Shiller's website $<$ www.econ.yale.edu/ ${ }^{\sim}$ shiller $/>$.
} 
revival, excess capital investment, and a stock market bubble fueled by speculation. Using data on newly-issued patents, Nicholas (2008) argues that the 1920s was "a period of unprecedented technological advance." Schwert $(1989,2002)$ documents the pronounced increase in stock market volatility that occurred during both periods, particularly in technology-related stocks in the late 1990s. Cooper et al. (2001) document a pronounced "dotcom effect" in the late 1990s, whereby internet-related corporate name changes produced permanent abnormal returns. The authors attribute their results to a form a speculative mania among investors for "glamour" industries that are associated with new technology.

Much of the surge in business investment in the late 1990s was linked to computers and information technology. During these years, measured productivity growth picked up, which was often cited as evidence of a permanent structural change - one that portended faster trend growth going forward. ${ }^{9}$ A recent analysis by Ireland and Schuh (2008) concludes that the productivity revival of the 1990s was temporary rather than permanent. But at the time, widespread belief in the so-called "new economy" caused investors to bid up stock prices to unprecedented levels relative to dividends (Figure 2). The rise and fall of potential output growth as measured by the Congressional Budget Office (CBO) coincides roughly with the rise and fall of cyclical movements in stock prices (Figure 3). The observed correlation between estimates of potential output growth and movements in the stock market motivates consideration of a model where equity price bubbles can affect the economy's trend growth rate.

Caballero et al. (2006) argue that rapidly rising stock prices in the late 1990s provided firms with a low-cost source of funds from which to finance their investment projects. Figure 4 shows that the trajectory of the S\&P 500 stock index, both before and after the bubble peak, is strikingly similar to the trajectory of investment.

On January 13, 2000, near the peak of the stock market, Fed Chairman Alan Greenspan discussed the possibility that productivity-enhancing innovations might have raised the U.S. economy's growth pace, but that investors might have overreacted to these developments:

"When we look back at the 1990s, from the perspective of say 2010...[w]e may conceivably conclude from that vantage point that, at the turn of the millennium, the American economy was experiencing a once-in-a-century acceleration of innovation, which propelled forward productivity, output, corporate profits, and stock prices at a pace not seen in generations, if ever. Alternatively, that 2010 retrospective might well conclude that a good deal of what we are currently experiencing was just one of the many euphoric speculative bubbles that have dotted human history. And, of course, we cannot rule out that we may look back and conclude that elements from both scenarios have been in play in recent years."

\footnotetext{
${ }^{9}$ For an optimistic assessment at the time, see Oliner and Sichel (2000). For a sceptical view, see Gordon (2000).
} 
The model presented here incorporates "elements from both scenarios" described by Greenspan. Figure 5 shows that one can observe similar comovement between asset prices and investment in the recent U.S. housing market. Real house prices rose sharply from 2000 to 2006 while real residential investment experienced an unprecedented boom. Both series then reversed course dramatically. An accommodative interest rate environment, combined with a proliferation of new mortgage products (loans with little or no down payment, minimal documentation of income, and payments for interest-only or less), helped fuel the run-up in house prices. While perhaps less obvious than with the late-1990s stock market bubble, one can make the case that over-enthusiasm for new technology played a role in the mid-2000s housing market boom.

On April 8, 2005, near the peak of the housing bubble, Fed Chairman Alan Greenspan offered the following optimistic assessment of new technology:

"[T]he financial services sector has been dramatically transformed by technology... Information processing technology has enabled creditors to achieve significant efficiencies in collecting and assimilating the data necessary to evaluate risk and make corresponding decisions about credit pricing. With these advances in technology, lenders have taken advantage of credit-scoring models and other techniques for efficiently extending credit to a broader spectrum of consumers... Where once more-marginal applicants would simply have been denied credit, lenders are now able to quite efficiently judge the risk posed by individual applicants and to price that risk appropriately. These improvements have led to rapid growth in subprime mortgage lending."

The subprime lending boom was later followed by a sharp rise in delinquencies and foreclosures, massive write-downs in the value of securities backed by subprime mortgages and derivatives, the collapse of several large financial institutions, and, ultimately, a serious financial crisis prompting unprecedented U.S. government intervention in private capital markets. In retrospect, Greenspan's enthusiasm for a "new era" in credit risk modeling appears a bit overdone.

\section{Model}

The representative agent is a capitalist-entrepreneur who maximizes

$$
E_{0} \sum_{t=0}^{\infty} \beta^{t}\left[\frac{c_{t}^{1-\alpha}-1}{1-\alpha}\right],
$$

subject to the budget constraint

$$
c_{t}+i_{t}=y_{t}, \quad c_{t}, i_{t}>0
$$


where $c_{t}$ is consumption, $i_{t}$ is investment, $y_{t}$ is output (or income), $\beta$ is the subjective time discount factor, and $\alpha$ is the coefficient of relative risk aversion (the inverse of the elasticity of intertemporal substitution). When $\alpha=1$, the within-period utility function can be written as $\log \left(c_{t}\right)$. The symbol $E_{t}$ represents the mathematical expectation operator.

Output is produced according to the technology

$$
\begin{aligned}
& y_{t}=A \exp \left(z_{t}\right) k_{t}^{\theta} h_{t}^{1-\theta}, A>0, \quad \theta \in(0,1], \\
& z_{t}=\rho z_{t-1}+\epsilon_{t}, \quad \epsilon_{t} \sim N\left(0, \sigma_{\epsilon}^{2}\right), \quad z_{0} \text { given, }
\end{aligned}
$$

where $k_{t}$ is the agent's stock of physical capital and $z_{t}$ represents a persistent, mean-reverting technology shock. When $\theta<1$, output is also affected by $h_{t}$, which represents the stock of human capital or knowledge. Following Arrow (1962) and Romer (1986), I assume that $h_{t}$ grows proportionally to, and as a by-product of, accumulated private investment activities. This "learning-by-doing" formulation is captured by the specification $h_{t}=K_{t}$, where $K_{t}$ is the economy-wide average capital stock per person which the agent takes as given. In equilibrium, all agents are identical, so we have $k_{t}=K_{t}$ which is imposed after the investment decision is made. When $\theta<1$, the private marginal product of capital is less than the social marginal product such that agents underinvest relative to the socially-optimal level.

Resources devoted to investment augment the stock of physical capital according to the law of motion

$$
k_{t+1}=B k_{t}^{1-\lambda} i_{t}^{\lambda}, \quad B>0, \quad \lambda \in(0,1], \quad k_{0} \text { given, }
$$

which reflects capital adjustment costs. This formulation has been employed previously by Cassou and Lansing (2006) in a welfare analysis of tax reform. Equation (5) can be interpreted as a log-linearized version of the following specification employed by Jermann (1998) and Barlevy (2004):

$$
\begin{aligned}
& \frac{k_{t+1}}{k_{t}}=1-\delta+\psi_{0}\left(\frac{i_{t}}{k_{t}}\right)^{\psi_{1}} \simeq B\left(\frac{i_{t}}{k_{t}}\right)^{\lambda}, \\
& \lambda=\frac{\psi_{0} \psi_{1}(\widetilde{i / k})^{\psi_{1}}}{1-\delta+\psi_{0}(\widetilde{i / k})^{\psi_{1}}}, \quad B=\frac{1-\delta+\psi_{0}(\widetilde{i / k})^{\psi_{1}}}{(\widetilde{i / k})^{\lambda}},
\end{aligned}
$$

where $\lambda$ and $B$ are Taylor-series coefficients and $\widetilde{i / k}=\exp \left\{E\left[\log \left(i_{t} / k_{t}\right)\right]\right\}$ is the approximation point..$^{10}$

The agent's first-order condition with respect to $k_{t+1}$ is given by

$$
\frac{i_{t} c_{t}^{-\alpha}}{\lambda k_{t+1}}=E_{t} \beta c_{t+1}^{-\alpha}\left[\frac{\theta y_{t+1}}{k_{t+1}}+\frac{(1-\lambda) i_{t+1}}{\lambda k_{t+1}}\right],
$$

\footnotetext{
${ }^{10}$ Since the functional form of the constraint affects the agent's intertemporal optimality condition, the economic environment considered here is not isomorphic to that of Jermann (1998) and Barlevy (2004).
} 
where $k_{t+1}$ is known at time $t$. The first-order condition can be rearranged to obtain the following standard asset pricing equation

$$
\underbrace{i_{t} / \lambda}_{p_{t}}=E_{t} \beta\left[\frac{c_{t+1}}{c_{t}}\right]^{-\alpha}[\underbrace{\theta y_{t+1}-i_{t+1}}_{d_{t+1}}+\underbrace{i_{t+1} / \lambda}_{p_{t+1}}],
$$

where $p_{t} \equiv i_{t} / \lambda$ is the ex-dividend price of an equity share with claim to a perpetual stream of dividends $d_{t}=\theta y_{t}-i_{t}$. When $\theta=1$, consumption is equal to dividends, analogous to the Lucas (1978) endowment economy. When $\theta<1$, consumption strictly exceeds dividends, owing to the presence of the learning-by-doing externality which can be viewed as separate source of income for the agent. The term $\beta\left(c_{t+1} / c_{t}\right)^{-\alpha}$ is the stochastic discount factor.

The model's adjustment cost specification (5) implies a direct link between the equity price $p_{t}$ and investment $i_{t}$, consistent with a standard Tobin's $q$ framework. This feature is also consistent with the observed comovement between U.S. stock prices and business investment shown in Figure 4. Although the model implies perfect comovement between $p_{t}$ and $i_{t}$, this prediction could be relaxed by introducing stochastic variation in the adjustment cost parameter $\lambda .^{11}$

The gross return from holding the equity share from period $t$ to $t+1$ is given by

$$
R_{t+1}=\frac{p_{t+1}+d_{t+1}}{p_{t}}=\frac{i_{t+1}}{i_{t}}\left[\frac{\lambda \theta y_{t+1}}{i_{t+1}}+1-\lambda\right]
$$

which shows that return volatility is driven by the volatility of investment growth and by the volatility of the output-investment ratio.

To facilitate a solution to the agent's problem, the first-order condition (8) must be rewritten in terms of stationary variables. If we define the price-consumption ratio as $x_{t} \equiv p_{t} / c_{t}=$ $\left(i_{t} / \lambda\right) / c_{t}$, then the budget constraint (2) can be used to derive the following expressions for the equilibrium allocations:

$$
\begin{aligned}
c_{t} & =\left[\frac{1}{1+\lambda x_{t}}\right] y_{t}, \\
i_{t} & =\left[\frac{\lambda x_{t}}{1+\lambda x_{t}}\right] y_{t}, \\
d_{t} & =\left[\frac{\theta-(1-\theta) \lambda x_{t}}{1+\lambda x_{t}}\right] y_{t},
\end{aligned}
$$

where $y_{t}=A \exp \left(z_{t}\right) k_{t}$ in equilibrium. The price-dividend ratio can be written as

$$
\frac{p_{t}}{d_{t}}=\frac{i_{t} / \lambda}{d_{t}}=\frac{x_{t}}{\theta-(1-\theta) \lambda x_{t}}
$$

\footnotetext{
${ }^{11}$ Lansing (2011) considers an adjustment cost specification that allows for stochastic variation in the relative contributions of new investment versus existing capital in the production of new capital goods.
} 
which is a non-linear function of the price-consumption ratio $x_{t}$. When there is no productive externality, we have $\theta=1$ such that $p_{t} / d_{t}=x_{t}$.

An expression for equilibrium consumption growth can be obtained by combining (10), (11), and (5) to yield

$$
\begin{aligned}
\frac{c_{t+1}}{c_{t}} & =\left[\frac{1+\lambda x_{t}}{1+\lambda x_{t+1}}\right] \frac{y_{t+1}}{y_{t}}=\left[\frac{1+\lambda x_{t}}{1+\lambda x_{t+1}}\right] \exp \left(z_{t+1}-z_{t}\right) \frac{k_{t+1}}{k_{t}} \\
& =B A^{\lambda}\left[\frac{\left(1+\lambda x_{t}\right)^{1-\lambda}\left(\lambda x_{t}\right)^{\lambda}}{1+\lambda x_{t+1}}\right] \exp \left[z_{t+1}-(1-\lambda) z_{t}\right] .
\end{aligned}
$$

Substituting the above expression into the first-order condition (8) together with $y_{t+1}=$ $c_{t+1}+i_{t+1}$ yields the following transformed version of the first-order condition in terms of stationary variables:

$$
\begin{array}{cc}
\frac{x_{t}^{1-\lambda \phi} \exp \left[\phi(1-\lambda) z_{t}\right]}{\left(1+\lambda x_{t}\right)^{(1-\lambda) \phi}}= & E_{t} \widetilde{\beta}\left[\frac{\theta+x_{t+1}(1-\lambda+\lambda \theta)}{\left(1+\lambda x_{t+1}\right)^{\phi}}\right] \exp \left(\phi z_{t+1}\right), \\
\phi \equiv 1-\alpha, & \widetilde{\beta} \equiv \beta\left[B(A \lambda)^{\lambda}\right]^{\phi} .
\end{array}
$$

The observed technology shock $z_{t}$ and the existing capital stock $k_{t}$ uniquely determine the amount of per capita output according to (3). Each period, the agent must only decide the fraction of available output to be devoted to investment, with the remaining fraction devoted to consumption. The investment-consumption ratio is given by $i_{t} / c_{t}=\lambda x_{t}$. Hence, the agent's decision problem can be formulated equivalently in terms of the price-consumption ratio $x_{t}$, which is a stationary variable.

\subsection{Rational Solution}

The transformed first-order condition (15) is a non-linear stochastic difference equation. Except for the special case of $\log$ utility $(\phi=0)$, an exact analytical solution cannot be obtained. To facilitate an approximate analytical solution, both sides of equation (15) are approximated as power functions around the points $\widetilde{x}=\exp \left\{E\left[\log \left(x_{t}\right)\right]\right\}$ and $\widetilde{z}=0$ to obtain:

$$
a_{0}\left[\frac{x_{t}}{\widetilde{x}}\right]^{a_{1}} \exp \left[\phi(1-\lambda) z_{t}\right]=E_{t} b_{0}\left[\frac{x_{t+1}}{\widetilde{x}}\right]^{b_{1}} \exp \left(\phi z_{t+1}\right),
$$

where $a_{0}, a_{1}, b_{0}$, and $b_{1}$ are Taylor-series coefficients that depend on $\widetilde{x}$, as defined in Appendix A. In equilibrium, movements in $x_{t}$ are driven solely by movements in the technology shock $z_{t}$. The approximate rational solution is given by the following proposition. 
Proposition 1. An approximate analytical solution for the rational price-consumption ratio is given by

$$
x_{t}=\widetilde{x} \exp \left(\gamma z_{t}\right)
$$

where $\widetilde{x}=\exp \left\{E\left[\log \left(x_{t}\right)\right]\right\}$ is the approximation point and $\gamma$ is given by

$$
\gamma=\frac{\phi[\rho-(1-\lambda)]}{a_{1}-\rho b_{1}}
$$

Proof: See Appendix A.

In the special case of logarithmic utility, we have $\phi=0$ such that $\gamma=0$, resulting in $x_{t}=\widetilde{x}$ for all $t$. From equation (13), the price-dividend ratio $p_{t} / d_{t}$ is also constant in the logarithmic case. When $\phi \neq 0$, the valuation ratios $x_{t}$ and $p_{t} / d_{t}$ respond to technology shocks. The direction of movement depends on the relative magnitudes of the income and substitution effects of the shock, which in turn are governed by the elasticity of intertemporal substitution (EIS), as given by $1 /(1-\phi)$. When $\alpha>1$, we have $\phi<0$, such that EIS $<1$. The sign of the technology response coefficient $\gamma$ depends not only on the sign of $\phi$, but also on the sign of $\rho-(1-\lambda) .{ }^{12}$ In the baseline calibration, the result is $\gamma>0$. When $\gamma>0$, the substitution effect of a positive technology shock dominates the income effect such that investment increases relative to consumption, thus causing the ratio $x_{t}=\left(i_{t} / \lambda\right) / c_{t}$ to rise. For moderate levels of risk aversion, $x_{t}$ and $p_{t} / d_{t}$ exhibit very little volatility because the income and substitution effects of a technology shock largely offset one another.

\subsection{Near-Rational Bubble Law of Motion}

The first-order condition (8) imposes a no-arbitrage condition from period $t$ to $t+1$. Since equation (8) does not enforce a transversality condition, it admits solutions where the equity price $p_{t}$ can deviate from the rational solution implied by fundamentals alone. So-called "rational bubble" solutions have been proposed as a way to account for the empirical observation that equity prices appear excessively volatile relative to a discounted stream of dividends or cash flows. The underlying assumption is that agents are forward-looking, but not to the extreme degree implied by the transversality condition. ${ }^{13}$

The equity price $p_{t}=i_{t} / \lambda$ in equation (8) can be disaggregated as follows

$$
p_{t}=p_{t}^{\mathrm{f}}+p_{t}^{\mathrm{b}}
$$

where $p_{t}^{\mathrm{f}}=i_{t}^{\mathrm{f}} / \lambda$ and $p_{t}^{\mathrm{b}}=i_{t}^{\mathrm{b}} / \lambda$ are the fundamental and bubble components of the equity price which are directly proportional to the fundamental and bubble components of investment,

\footnotetext{
${ }^{12}$ For all calibrations examined, $a_{1}-\rho b_{1}>0$.

${ }^{13}$ See Lansing (2010) for a review of the literature on rational bubbles and the numerous theoretical caveats that govern their existence.
} 
denoted by $i_{t}^{\mathrm{f}}$ and $i_{t}^{\mathrm{b}}$. Substituting the above equation into (8) yields the following pair of no-arbitrage conditions:

$$
\begin{aligned}
& \underbrace{i_{t}^{\mathrm{f}} / \lambda}_{p_{t}^{\mathrm{f}}}=E_{t} \beta\left[\frac{c_{t+1}}{c_{t}}\right]^{-\alpha}[\underbrace{\theta y_{t+1}-i_{t+1}^{\mathrm{f}}-i_{t+1}^{\mathrm{b}}}_{d_{t+1}}+\underbrace{i_{t+1}^{\mathrm{f}} / \lambda}_{p_{t+1}^{\mathrm{f}}}] \\
& \underbrace{i_{t}^{\mathrm{b}} / \lambda}_{p_{t}^{\mathrm{b}}}=E_{t} \beta\left[\frac{c_{t+1}}{c_{t}}\right]^{-\alpha} \underbrace{i_{t+1}^{\mathrm{b}} / \lambda}_{p_{t+1}^{\mathrm{b}}} .
\end{aligned}
$$

In equation (18), the fundamental component of the equity price $p_{t}^{\mathrm{f}}$ is equal to the expected discounted value of next period's payoff amount $d_{t+1}+p_{t+1}^{\mathrm{f}}$. In contrast to a Lucas (1978) type model where consumption and dividends are exogenous, the bubble component here influences both the stochastic discount factor $\beta\left(c_{t+1} / c_{t}\right)^{-\alpha}$ and the dividend $d_{t+1}$. Hence, feedback from the bubble component affects the fundamental equity price, similar to the model of Weil (1990). In equation (19), the bubble component of the equity price $p_{t}^{\mathrm{b}}$ is equal to the expected discounted value of next period's bubble price $p_{t+1}^{\mathrm{b}}$, with no regard for dividends. Hence, while the bubble component of investment $i_{t}^{\mathrm{b}}$ augments the stock of physical capital via equation (5), the shareholders who supply the investment funds to the capitalist-entrepreneur receive no claim to any extra dividends; their expected return on the additional funds derives solely from the prospect for price appreciation of their shares.

Defining $x_{t}^{\mathrm{f}} \equiv p_{t}^{\mathrm{f}} / c_{t}$ and $x_{t}^{\mathrm{b}} \equiv p_{t}^{\mathrm{b}} / c_{t}$, the no-arbitrage conditions (18) and (19) can be written as

$$
\begin{aligned}
& x_{t}^{\mathrm{f}}=E_{t} \beta\left[\frac{c_{t+1}}{c_{t}}\right]^{\phi}\left[\theta+x_{t+1}^{\mathrm{f}}(1-\lambda+\lambda \theta)-x_{t+1}^{\mathrm{b}} \lambda(1-\theta)\right], \\
& x_{t}^{\mathrm{b}}=E_{t} \beta\left[\frac{c_{t+1}}{c_{t}}\right]^{\phi} x_{t+1}^{\mathrm{b}},
\end{aligned}
$$

where $\phi \equiv 1-\alpha$ and have I substituted in $y_{t+1}=c_{t+1}+i_{t+1}^{\mathrm{f}}+i_{t+1}^{\mathrm{b}}$. Equation (21) implies that the bubble component of the price-consumption ratio $x_{t}^{\mathrm{b}}$ must grow over time in expectation by a sufficient amount to offset the discounting implied by the stochastic discount factor. A rational bubble solution that satisfies (21) exactly would thus deliver the result that $x_{t}^{\mathrm{b}}$ is non-stationary, ruling out the existence of a balanced growth path. Moreover, as shown by Lansing (2010), there can be a continuum of rational bubble solutions that satisfy the no-arbitrage condition, with solutions along the continuum exhibiting different equilibrium responses to fundamental state variables. The representative agent must postulate a solution for $x_{t}^{\mathrm{b}}$ in order to evaluate the conditional expectation on the right side of the no-arbitrage condition. For risk aversion coefficients near unity, the no-arbitrage condition can be written as $x_{t}^{\mathrm{b}} \simeq \beta E_{t} x_{t+1}^{\mathrm{b}}$. which shows that the postulated solution can have a strong influence on the 
resulting no-arbitrage value. Depending on the functional form of the postulated solution, the agent's expectations may become self-fulfilling, allowing for multiple rational bubble solutions.

To sidestep the complications associated with rational bubbles, I postulate the following stationary law of motion for the bubble component:

$$
x_{t}^{\mathrm{b}}=x_{t}^{\mathrm{f}}\left[\exp \left(\gamma^{\mathrm{b}} z_{t}\right)-1\right],
$$

where $\gamma^{\mathrm{b}}$ is a parameter that governs the response to observed technology shocks. The bubble is "intrinsic" in the terminology of Froot and Obstfeld (1991) because the bubble law of motion depends solely on fundamentals; there are no extraneous shocks or sunspot variables. Consistent with the historical examples provided by Shiller (2000), equation (22) implies that fundamental technology innovations are important to investors, but their effects are amplified whenever $\gamma^{\mathrm{b}}>0$. Under this formulation, a sequence of sufficiently large technology innovations can produce large excursions away from the fundamental equity price. Notice that for any value of $\gamma^{\mathrm{b}}$, the bubble law of motion satisfies the no-arbitrage condition (21) exactly when $z_{t}=z_{t+1}=0$. Later, in the model simulations, I will show that the bubble law of motion is "near-rational" in the sense that it approximately satisfies the no-arbitrage condition for most realizations of $z_{t}$ and $z_{t+1}$. Unlike a rational bubble solution, the near-rational law of motion allows the equity price to occasionally dip below the equilibrium value implied by Proposition 1 for the bubble-free economy.

\subsection{Fundamental Solution in the Bubble Economy}

The expression for $c_{t+1} / c_{t}$ in the bubble economy takes the same form as equation (14), but now $x_{t}=x_{t}^{\mathrm{f}}+x_{t}^{\mathrm{b}}$. Similarly, the form of equations (10) through (13) carry over to the bubble economy. Substituting $c_{t+1} / c_{t}$ from equation (14) into the fundamental no-arbitrage condition (20) and then also substituting in $x_{t}=x_{t}^{\mathrm{f}}+x_{t}^{\mathrm{b}}$, with $x_{t}^{\mathrm{b}}$ given by the bubble law of motion (22) yields the following equation that governs the evolution of the fundamental price-consumption ratio $x_{t}^{\mathrm{f}}$ in the bubble economy:

$$
\frac{\left(x_{t}^{\mathrm{f}}\right)^{1-\lambda \phi} \exp \left[\phi\left(1-\lambda-\lambda \gamma^{\mathrm{b}}\right) z_{t}\right]}{\left[1+\lambda x_{t}^{\mathrm{f}} \exp \left(\gamma^{\mathrm{b}} z_{t}\right)\right]^{(1-\lambda) \phi}}=E_{t} \widetilde{\beta}\left\{\frac{\theta+x_{t+1}^{\mathrm{f}}\left[1-\lambda(1-\theta) \exp \left(\gamma^{\mathrm{b}} z_{t+1}\right)\right]}{\left[1+\lambda x_{t+1}^{\mathrm{f}} \exp \left(\gamma^{\mathrm{b}} z_{t+1}\right)\right]^{\phi}}\right\} \exp \left(\phi z_{t+1}\right),
$$

where $\phi$ and $\widetilde{\beta}$ are defined as before. The above expression collapses to equation (15) when $\gamma^{\mathrm{b}}=0$ such that $x_{t}=x_{t}^{\mathrm{f}}$.

To facilitate an approximate analytical solution for $x_{t}^{\mathrm{f}}$, I proceed as before and approximate both sides of equation (23) as power functions around the points $\widetilde{x}^{\mathrm{f}}=\exp \left\{E\left[\log \left(x_{t}^{\mathrm{f}}\right)\right]\right\}$ and $\widetilde{z}=0$ to obtain:

$$
a_{0}^{\mathrm{f}}\left[\frac{x_{t}^{\mathrm{f}}}{\widetilde{x}^{\mathrm{f}}}\right]^{a_{1}^{\mathrm{f}}} \exp \left(a_{2}^{\mathrm{f}} z_{t}\right)=E_{t} b_{0}^{\mathrm{f}}\left[\frac{x_{t+1}^{\mathrm{f}}}{\widetilde{x}^{\mathrm{f}}}\right]^{b_{1}^{\mathrm{f}}} \exp \left(b_{2}^{\mathrm{f}} z_{t+1}\right)
$$


where $a_{0}^{\mathrm{f}}, a_{1}^{\mathrm{f}}, a_{2}^{\mathrm{f}}, b_{0}^{\mathrm{f}}, b_{1}^{\mathrm{f}}$, and $b_{2}^{\mathrm{f}}$ are Taylor-series coefficients that depend on $\widetilde{x}^{\mathrm{f}}$ and $\gamma^{\mathrm{b}}$, as shown in Appendix B. The approximate fundamental solution is given by the following proposition.

Proposition 2. An approximate analytical solution for the fundamental price-consumption ratio in the bubble economy is given by

$$
x_{t}^{\mathrm{f}}=\widetilde{x}^{\mathrm{f}} \exp \left(\gamma^{\mathrm{f}} z_{t}\right),
$$

where $\widetilde{x}^{\mathrm{f}}=\exp \left\{E\left[\log \left(x_{t}^{\mathrm{f}}\right)\right]\right\}$ is the approximation point and $\gamma^{\mathrm{f}}$ is given by

$$
\gamma^{\mathrm{f}}=\frac{\rho b_{2}^{\mathrm{f}}-a_{2}^{\mathrm{f}}}{a_{1}^{\mathrm{f}}-\rho b_{1}^{\mathrm{f}}}
$$

Proof: See Appendix B.

Substituting the laws of motion for $x_{t}^{\mathrm{f}}$ and $x_{t}^{\mathrm{b}}$ into the definitional relationship $x_{t}=x_{t}^{\mathrm{f}}+x_{t}^{\mathrm{b}}$ yields the following approximate expression for the total price-consumption ratio

$$
x_{t}=\widetilde{x}^{\mathrm{f}} \exp \left[(\underbrace{\gamma^{\mathrm{f}}}_{\substack{\text { depends } \\ \text { on } \gamma^{\mathrm{b}}}}+\gamma^{\mathrm{b}}) z_{t}\right],
$$

which collapses to the rational solution from Proposition 1 when $\gamma^{\mathrm{b}}=0$ or when $z_{t}=0$. The above equation implies $E\left[\log \left(x_{t}\right)\right]=E\left[\log \left(x_{t}^{\mathrm{f}}\right)\right]$. When $\gamma^{\mathrm{b}}>0$, the price-consumption ratio "overreacts" to innovations in technology, thereby generating excess volatility.

The total price-dividend ratio is given by

$$
\frac{p_{t}}{d_{t}}=\frac{p_{t}^{\mathrm{f}}+p_{t}^{\mathrm{b}}}{d_{t}}=\frac{x_{t}}{\theta-(1-\theta) \lambda x_{t}}
$$

where $x_{t}=x_{t}^{\mathrm{f}}+x_{t}^{\mathrm{b}}$. Due to the non-linear nature of the above equation, the presence of excess volatility in $x_{t}$ can generate sharp run-ups and crashes in the price-dividend ratio which resemble patterns observed in long-run U.S. data.

\section{Model Calibration}

A time period in the model is taken to be one year. The technology response parameter $\gamma^{\mathrm{b}}$ in the bubble law of motion (22) is calibrated so that the bubble model matches the volatility of the price-dividend ratio in long-run annual U.S. data. This method of calibrating $\gamma^{\mathrm{b}}$ is analogous to the manner in which the exogenous crash probability parameter might be chosen in a particular class of rational bubble models. ${ }^{14}$ The remaining parameters of the model

\footnotetext{
${ }^{14}$ The procedure for calibrating $\gamma^{\mathrm{b}}$ abstracts from the underlying source of excess volatility. Reduced-form modeling devices such as this are often employed in macroeconomics. Examples include Calvo-type sticky price models which abstract from the underlying source of price stickiness, or money-in-the-utility-function models which abstract from the underlying role played by money in facilitating transactions.
} 
are chosen simultaneously to match various empirical targets, as summarized in Table 1. For example, the volatility of the technology shock innovation $\sigma_{\epsilon}$ is chosen so that the model matches the standard deviation of real per capita consumption growth in long-run annual U.S. data. Appendix C contains the approximate analytical moments that are used as a starting point to calibrate the nonlinear model.

The rational model employs the same parameter values as the bubble model, except that $\gamma^{\mathrm{b}}=0$ for the rational model. I examine a range of values for the externality parameter $\theta$ and the risk aversion coefficient $\alpha$. Specifically, I consider $\theta \in\{0.4,0.6,1.0\}$ and $\alpha \in$ $\{0.5,1.0,1.5,2.0,2.5\}$. The baseline calibration is $\theta=0.4$ and $\alpha=1.5$. Whenever $\theta$ or $\alpha$ is changed, the remaining parameters are re-adjusted to maintain the same targets shown in Table 1.

Given the calibrated values of $\lambda$ and $B$ shown in Table 1, equation (6) can be used to recover the implied curvature parameter $\psi_{1}$ for comparison with Barlevy (2004). Assuming an annual depreciation rate of $\delta=0.1$, equation (6) yields $\psi_{1}=0.59$ when $\theta=0.4$, and yields $\psi_{1}=0.12$ when $\theta=1.0$. Barlevy (2004) considers values in the range $0.12 \leq \psi_{1} \leq 0.26$ for an endogenous growth model that corresponds to the $\theta=1.0$ case. As $\psi_{1} \rightarrow 1.0$, the implied adjustment costs approach zero. Hence, the calibration methodology used here delivers lower implied adjustment costs when $\theta<1$.

Table 1: Example Calibrations for the Bubble Model

\begin{tabular}{ccccl}
\hline \hline Parameter & \multicolumn{3}{c}{ Value } & \multicolumn{1}{c}{ Description/Empirical Target } \\
\hline$\theta$ & 0.4 & 0.6 & 1.0 & Capital share of income. \\
$\alpha$ & 1.5 & 1.5 & 1.5 & Coefficient of relative risk aversion. \\
$A$ & 0.333 & 0.333 & 0.333 & Mean capital-output ratio $=3$. \\
$\lambda$ & 0.071 & 0.030 & 0.014 & Mean investment-output ratio $=0.25$. \\
$B$ & 1.217 & 1.100 & 1.056 & Mean consumption growth $=2.03 \%$. \\
$\sigma_{\epsilon}$ & 0.054 & 0.072 & 0.086 & Standard deviation of consumption growth $=3.51 \%$. \\
$\rho$ & 0.9 & 0.9 & 0.9 & Corr. $\left(p_{t} / d_{t}, p_{t-1} / d_{t-1}\right) \simeq 0.9$. \\
$\beta$ & 0.968 & 0.969 & 0.970 & Mean price-dividend ratio $=26.6$. \\
$\gamma^{\mathrm{b}}$ & 2.305 & 2.410 & 2.560 & Standard deviation of price-dividend ratio $=13.8$. \\
\hline
\end{tabular}

When $\theta=0.4$ and $\alpha=1.5$, the parameter values in Table 1 yield $\gamma=0.069$ in the rational model from Proposition 1 and $\gamma^{\mathrm{f}}=-0.752$ in the bubble model from Proposition 2 . The presence of the bubble thus alters the nature of the fundamental solution. The small positive value of $\gamma$ in the rational model implies that a favorable technology shock brings about a small increase in the ratio $i_{t} / c_{t}$. But in the bubble model, we have $\gamma^{\mathrm{f}}+\gamma^{\mathrm{b}}=1.55$, so that a favorable technology shock brings about a large increase in the ratio $i_{t} / c_{t}$, thereby magnifying the volatility of the equity price relative to consumption and dividends. When a favorable technology shock increases the bubble component of investment, less resources are available for paying dividends which are given by $\theta y_{t}-i_{t}$. All else equal, a dividend cut pushes down the fundamental component of the equity price and fundamental investment. The fact that 
$\gamma^{\mathrm{f}}<0$ shows that the fundamental investment response serves to partially undo the extra investment induced by the bubble.

\section{$5 \quad$ Near-Rational Bubble Dynamics}

The top panel of Figure 6 checks the conformance of the bubble law of motion (22) with the no-arbitrage condition (21) for the baseline calibration with $\theta=0.4$ and $\alpha=1.5$. Other calibrations produced similar results. To construct the no-arbitrage value, I employ the following power-function approximation for consumption growth that is derived in Appendix C:

$$
\frac{c_{t+1}}{c_{t}}=\exp \left(\widetilde{\mu}^{\mathrm{f}}\right)\left[\frac{x_{t+1}}{\widetilde{x}^{\mathrm{f}}}\right]^{h_{1}}\left[\frac{x_{t}}{\widetilde{x}^{\mathrm{f}}}\right]^{h_{2}} \exp \left[z_{t+1}-(1-\lambda) z_{t}\right]
$$

where $\widetilde{\mu}^{\mathrm{f}}$ is the endogenous trend growth rate of consumption that depends on $\widetilde{x}^{\mathrm{f}}$ and $\gamma^{\mathrm{b}}$, and $h_{1}$ and $h_{2}$ are Taylor-series coefficients. To evaluate the conditional expectation on the right side of the no-arbitrage condition, I insert the approximate laws of motion for $x_{t+1}$ and $x_{t}$ from equation (25) into the consumption growth equation (27), resulting in the following expression:

$$
\begin{aligned}
\beta\left[\frac{c_{t+1}}{c_{t}}\right]^{\phi} x_{t+1}^{\mathrm{b}}= & \beta \exp \left\{\phi \widetilde{\mu}^{\mathrm{f}}+\phi\left[h_{1}\left(\gamma^{\mathrm{f}}+\gamma^{\mathrm{b}}\right)+1\right] z_{t+1}+\phi\left[h_{2}\left(\gamma^{\mathrm{f}}+\gamma^{\mathrm{b}}\right)-1+\lambda\right] z_{t}\right\} x_{t+1}^{\mathrm{b}} \\
= & \beta \widetilde{x}^{\mathrm{f}} \exp \left\{\phi \tilde{\mu}^{\mathrm{f}}+\phi\left[h_{2}\left(\gamma^{\mathrm{f}}+\gamma^{\mathrm{b}}\right)-1+\lambda\right] z_{t}\right\} \\
& \times \exp \left\{\phi\left[h_{1}\left(\gamma^{\mathrm{f}}+\gamma^{\mathrm{b}}\right)+1\right] z_{t+1}\right\} \\
& \times\left\{\exp \left[\left(\gamma^{\mathrm{f}}+\gamma^{\mathrm{b}}\right) z_{t+1}\right]-\exp \left(\gamma^{\mathrm{f}} z_{t+1}\right)\right\}
\end{aligned}
$$

where I have also substituted in the postulated bubble law of motion for $x_{t+1}^{\mathrm{b}}$ from equation (22). The second line of the equation groups terms that are known at time $t$. Given the stochastic process for $z_{t+1}$, the conditional expectation of the above expression can be computed analytically each period to provide a no-arbitrage value for $x_{t}^{\mathrm{b}}$ that satisfies equation (21) by construction.

Similarly, the bottom panel of Figure 6, checks the conformance of the total price-consumption ratio $x_{t}$ with the following no-arbitrage condition implied by the first-order condition (8):

$$
x_{t}=E_{t} \beta\left[\frac{c_{t+1}}{c_{t}}\right]^{\phi}\left[\theta+x_{t+1}(1-\lambda+\lambda \theta)\right] .
$$

To evaluate the conditional expectation on the right-side of the above expression, I again make use of the consumption growth approximation (27) together with the approximate laws of motion for $x_{t+1}$ and $x_{t}$ from equation (25). As before, the conditional expectation is computed analytically each period to provide a no-arbitrage value for $x_{t}$ that satisfies equation (29) by construction. 
Figure 6 plots the constructed no-arbitrage values versus $x_{t}^{\mathrm{b}}$ and $x_{t}$ from the calibrated model. In both cases, there is close agreement between the two series except for extreme realizations of the technology shock that correspond to extreme readings for $x_{t}^{\mathrm{b}}$. Recall that the postulated bubble law of motion satisfies the no-arbitrage condition exactly when $z_{t}=$ $z_{t+1}=0$. But even for moderate shock realizations, there is close agreement between the two series showing that there is little opportunity for arbitrage. Intuitively, due to the selfreferential nature of the no-arbitrage conditions, the postulated law of motion for the bubble component is close to self-fulfilling.

An $\mathrm{AR}(1)$ regression on data for $x_{t}^{\mathrm{b}}$ generated by the calibrated law of motion (22) yields $x_{t}^{\mathrm{b}}=0.897 x_{t-1}^{\mathrm{b}}+0.002$. Whereas the typical rational bubble solution yields non-stationary behavior for the price-consumption ratio, the near-rational bubble considered here is stationary but highly persistent.

A natural question to ask is whether the postulated bubble law of motion (22) is learnable. Similar to the near-rational bubble solution presented in Lansing (2010), equation (22) is underparameterized relative to a rational bubble solution that would satisfy the no-arbitrage condition (21) exactly. Given data on $x_{t}, x_{t}^{\mathrm{f}}$, and $z_{t}$, the agent could estimate the technology response parameter for the near-rational bubble component as follows

$$
\gamma^{\mathrm{b}}=\frac{\operatorname{Cov}\left[\log \left(x_{t} / x_{t}^{\mathrm{f}}\right), z_{t}\right]}{\operatorname{Var}\left(z_{t}\right)},
$$

where $x_{t}=x_{t}^{\mathrm{f}}+x_{t}^{\mathrm{b}}$. In a typical real-time learning algorithm, the most-recent estimate of $\gamma^{\mathrm{b}}$ would be allowed to influence the evolution of $x_{t}^{\mathrm{f}}$ and $x_{t}^{\mathrm{b}}$ by solving (20) and (21) each period, where the agent's conditional forecasts would be computed using the postulated law of motion, as in equation (28) above. The agent's estimate of $\gamma^{\mathrm{b}}$ would then be updated and the simulation continued until some sort of convergence criteria is achieved. ${ }^{15}$ As an approximation to such an algorithm, I generate data for $x_{t}^{\mathrm{f}}$ and $x_{t}^{\mathrm{b}}$ under the baseline calibration with $\theta=0.4$ and $\alpha=1.5$. The data is generated by jointly solving the no-arbitrage conditions (20) and (21), with $\gamma^{\mathrm{b}}=2.305$ (the postulated value). The agent's conditional forecasts are computed using the postulated law of motion (22). Using this data, the estimated technology response parameter from equation (30) is $\gamma^{\mathrm{b}}=2.1$, which is reasonably close to the postulated value used to generate the data. From the agent's perspective, sampling variation in the covariance between $\log \left(x_{t} / x_{t}^{\mathrm{f}}\right)$ and $z_{t}$ could account for the deviation between the estimated value and the postulated value. Qualitatively similar results are obtained for other calibrations. Hence, to a first approximation, the postulated law of motion for the bubble is consistent with data generated by an actual law of motion.

\footnotetext{
${ }^{15}$ For examples of real-time learning algorithms along these lines, see Lansing (2009, section 4.1) and Lansing (2010, section 4.3).
} 


\section{Model Simulations}

This section demonstrates the ability of the bubble model to match various features of long-run U.S. data.

Table 2 presents unconditional moments computed from long simulations, where $\mu_{t+1}^{d} \equiv$ $\log \left(d_{t+1} / d_{t}\right)$ and $\mu_{t+1}^{c} \equiv \log \left(c_{t+1} / c_{t}\right)$ are the growth rates of dividends and consumption, respectively. The table also reports the corresponding statistics from long-run U.S. data. ${ }^{16}$

Table 2: Unconditional Asset Pricing Moments

\begin{tabular}{lccc}
\hline \hline Statistic & U.S. Data & $\begin{array}{c}\text { Rational } \\
\text { Model }\end{array}$ & $\begin{array}{c}\text { Bubble } \\
\text { Model }\end{array}$ \\
\hline Mean $p_{t} / d_{t}$ & 26.6 & 23.0 & 26.5 \\
Std. Dev. & 13.8 & 0.38 & 13.8 \\
Skew. & 2.20 & 0.03 & 4.23 \\
Kurt. & 8.21 & 2.94 & 44.3 \\
Corr. Lag 1 & 0.93 & 0.90 & 0.84 \\
\hline Mean $R_{t+1}$ & $7.84 \%$ & $6.66 \%$ & $7.27 \%$ \\
Std. Dev. & $17.8 \%$ & $6.06 \%$ & $12.1 \%$ \\
Corr. Lag 1 & 0.04 & -0.04 & -0.06 \\
\hline Mean $\mu_{t+1}^{d}$ & $1.37 \%$ & $2.03 \%$ & $2.04 \%$ \\
Std. Dev. & $11.7 \%$ & $4.96 \%$ & $8.25 \%$ \\
Corr. Lag 1 & 0.13 & -0.03 & -0.03 \\
\hline Mean $\mu_{t+1}^{c}$ & $2.03 \%$ & $2.03 \%$ & $2.04 \%$ \\
Std. Dev. & $3.51 \%$ & $5.33 \%$ & $3.51 \%$ \\
Corr. Lag 1 & -0.07 & -0.03 & 0.21 \\
\hline Note: Model statistics are from a 15,000 period simulation with $\theta=0.4, \alpha=1.5$.
\end{tabular}

Recall that the bubble model is calibrated to match the mean and volatility of the pricedividend ratio in the data. But the model also does a reasonably good job of matching other asset pricing moments. In particular, the U.S. price-dividend ratio exhibits positive skewness and excess kurtosis, which suggest the presence of nonlinearities in the data. The bubble model is able to capture these features because excess volatility in $x_{t}$, together with the nonlinear form of equations (22), (23), and (26), produces intermittent run-ups and crashes in the price-dividend ratio. In contrast, the rational model delivers very low volatility, near-zero skewness, and no excess kurtosis. The persistence of the price-dividend ratio in both models is inherited from the persistent technology shock process with $\rho=0.9$.

The mean equity return for both models is just slightly below the long-run U.S. average of $7.84 \%$. The volatility of returns in the bubble model is about twice that of the rational model $(12.1 \%$ versus $6.06 \%)$, but somewhat below the return volatility of $17.8 \%$ in the data. Equation

\footnotetext{
${ }^{16}$ The sample periods for the U.S. data shown in Table 3 are as follows: price-dividend ratio 1871-2008, real equity return 1871-2008, real dividend growth 1872-2008, real per capita consumption growth 1890-2008. The price-dividend ratio in year $t$ is defined as the value of the S\&P 500 stock index at the beginning of year $t+1$, divided by the accumulated dividend over year $t$.
} 
(9) shows how excess volatility in investment contributes directly to excess volatility in the equity return. The reason the bubble model underpredicts the U.S. return volatility is because it underpredicts the volatility of dividend growth, which is one component of the return. The volatility of dividend growth in the bubble model is $8.25 \%$ whereas the corresponding figure in U.S. data is $11.7 \%$. From equation (12), the volatility of dividend growth could be increased by introducing stochastic variation in either the production function parameter $\theta$ or the capital adjustment cost parameter $\lambda$.

The bubble model is calibrated to match the first and second moments of per capita consumption growth in the data. Consumption growth in the bubble model exhibits small positive serial correlation, with a correlation coefficient of 0.21 , whereas the correlation coefficient in the data is slightly negative at -0.07 . In post-World War II U.S. consumption data, however, the correlation coefficient is around 0.20 .

Figure 7 plots simulations from both models for the baseline calibration with $\theta=0.4$ and $\alpha=1.5$. In the top left panel, the highly persistent and volatile nature of the price-dividend ratio in the bubble model gives rise to intermittent excursions away from the rational model value. The behavior of the model price-dividend ratio looks qualitatively similar to the U.S. data shown earlier in Figure 2. With $\gamma^{\mathrm{b}}>0$, the bubble component of the equity price increases in response to a positive technology shock, as does the total price-dividend ratio because $\gamma^{\mathrm{f}}+\gamma^{\mathrm{b}}>0$. The technology-driven bubble episodes in the model coincide with economic booms and excess capital formation, as shown in the lower panels of Figure 7 . Interestingly, the bubble model can also generate prolonged periods where the price-dividend ratio remains in close proximity to the rational value. This is because the bubble component remains close to zero so long as technology shocks remain small. Consequently, only a fraction of the cyclical fluctuations in the model are due to bubble-like episodes.

Table 3 compares the volatilities of the model growth rates to those in the data. ${ }^{17}$ In the rational model, the presence of capital adjustment costs makes the volatility of investment growth about the same as the volatility of output growth, which is counterfactual. In longrun U.S. data, investment growth is about three times more volatile than output growth. By construction, the bubble model magnifies equity price volatility which is linked directly to the volatility of investment growth. Given that output growth volatility in the two models is about the same, the excess volatility of investment growth in the bubble model results in a lower volatility of consumption growth relative to the rational benchmark. This result has implications for the welfare analysis, which is discussed in the next section.

Figure 8 plots annual growth rates of macroeconomic variables from model simulations. The excess volatility of investment growth in the bubble model not only magnifies the volatility of dividend growth (bringing it closer to the data) but it also changes the cyclical pattern of

\footnotetext{
${ }^{17}$ Data on per capita real GDP from 1870-2008 was obtained from <www.globalfinancialdata.com $>$. Data on real business fixed investment from 1929-2008 was obtained from the U.S. Bureau of Economic Analysis/Haver Analytics.
} 
dividend growth relative to the rational model. This is because an increase in the bubble component of investment absorbs resources that could otherwise be paid out as dividends.

Table 3: Volatility of Real Growth Rates

\begin{tabular}{lcccc}
\hline \hline Variable & Dates & $\begin{array}{c}\text { U.S. } \\
\text { Economy }\end{array}$ & $\begin{array}{c}\text { Rational } \\
\text { Model }\end{array}$ & $\begin{array}{c}\text { Bubble } \\
\text { Model }\end{array}$ \\
\hline$\Delta \log \left(y_{t}\right)$ & $1871-2008$ & 5.28 & 5.42 & 5.45 \\
$\Delta \log \left(c_{t}\right)$ & $1890-2008$ & 3.51 & 5.33 & 3.51 \\
$\Delta \log \left(d_{t}\right)$ & $1872-2008$ & 11.7 & 4.96 & 8.25 \\
$\Delta \log \left(i_{t}\right)$ & $1930-2008$ & 16.2 & 5.71 & 11.8 \\
$\Delta \log \left(p_{t}\right)$ & $1872-2008$ & 17.9 & 5.71 & 11.8 \\
\hline
\end{tabular}

Note: In percent, from 15,000 period simulation with $\theta=0.4, \alpha=1.5$.

\section{Welfare Analysis}

This section examines the welfare costs of fluctuations that can be attributed to either: (i) speculative bubbles, or (ii) business cycles. Details of the welfare computations are contained in Appendix E. Expected lifetime utility in each economy is approximated by the average over 5000 simulations, each 2500 periods in length, after which the results are not changed. Welfare costs are measured by the percentage change in per-period consumption that makes the agent indifferent between the two economies being compared. Given annual U.S. consumption expenditures of around $\$ 10$ trillion in 2009, a one percent change in per-period consumption translates into an aggregate welfare cost of $\$ 100$ billion per year, which is equivalent to an annual cost of $\$ 855$ per household, based on an estimate of about 117 million U.S. households in $2009 .{ }^{18}$

The basic intuition underlying the welfare results is as follows:

- Bubbles direct more resources to investment on average which can help address the economy's underinvestment problem when $\theta<1$.

- However, when $\theta=1$, bubbles cause over-investment and under-consumption on average.

- Bubbles raise the volatility of investment, which leads to inefficiency in the production of new capital due to convex adjustment costs.

- As a mitigating factor, excess volatility in investment implies lower volatility in consumption growth relative to the rational model.

Which of these various effects dominate depends crucially on parameter values. It turns out that bubbles can be welfare-improving when risk aversion is low and the underinvestment

\footnotetext{
${ }^{18}$ Data on aggregate U.S. consumption and the number of U.S. households are from Haver Analytics.
} 
problem is severe. Table 4 summarizes some moments that influence the welfare computation. ${ }^{19}$ For each value of the risk coefficient $\alpha$, the bubble model is calibrated to match the mean and volatility of per capita consumption growth in long-run U.S. data. The rational model uses the same parameter values as the bubble model. The deterministic model sets $z_{t}=0$ for all $t$ such that the $i_{t} / k_{t}$ ratio and the growth rate of consumption are both constant at their deterministic steady-state values. As described in Appendix E, the initial level of consumption in the deterministic model differs from the average initial consumption levels in the fluctuating models.

Table 4 shows that the mean $i_{t} / k_{t}$ ratio is highest in the bubble model. This result follows directly from the bubble law of motion (22) which implies $E\left(x_{t}^{\mathrm{b}}\right)=E\left[i_{t}^{\mathrm{b}} /\left(\lambda c_{t}\right)\right]>0$, i.e., the bubble-component of investment is positive on average. Since the bubble model directs more resources to investment on average, it helps to address the economy's underinvestment problem whenever $\theta<1$. But when $\theta=1$, the bubble model is characterized by overinvestment which serves to reduce welfare.

The bubble model is also characterized by higher volatility of the $i_{t} / k_{t}$ ratio, which leads to inefficiency in the production of new capital due to the convex adjustment costs embedded in the capital law of motion (5). Figure 9 plots the model relationship between gross capital growth $k_{t+1} / k_{t}$ and the investment-capital ratio $i_{t} / k_{t}$. The upward-sloping dashed straight line (in red) is the hypothetical relationship implied by a linear law of motion with no adjustment costs and a constant annual depreciation rate, i.e., $k_{t+1} / k_{t}=1-\delta+i_{t} / k_{t}$. The hypothetical constant depreciation rate is computed from the bubble model simulations as $\delta=1+E\left(i_{t} / k_{t}\right)-$ $E\left(k_{t+1} / k_{t}\right)=0.064$. The vertical intercept of the hypothetical relationship is $1-\delta$. Comparing the slope of the straight line (equal to 1.0) to the slope of the model relationship (equal to $0.845)$ shows that capital adjustment costs are relatively small on average, i.e., when $i_{t} / k_{t}=$ $E\left(i_{t} / k_{t}\right)=0.086$. The figure also depicts \pm 1 standard deviation bands around the mean $i_{t} / k_{t}$ ratio from the simulations. The slope of the model relationship can vary between 0.64 and 1.23 as the $i_{t} / k_{t}$ ratio varies above or below its mean value by one standard deviation.

Since the capital law of motion implies $k_{t+1} / k_{t}=B\left(i_{t} / k_{t}\right)^{\lambda}$, a mean-preserving increase in the volatility of $i_{t} / k_{t}$ will lower the mean growth rate of the capital stock $k_{t+1} / k_{t}$, which in turn influences the mean growth rate of consumption. Excess volatility in the ratio $i_{t} / k_{t}$ thus tends to waste resources that could otherwise be used to support capital formation and growth. But as a mitigating factor, the bubble model lowers the volatility of consumption growth relative to the rational model, as noted earlier in the description of Table 3 . When risk aversion is low and the underinvestment problem is severe, the positive welfare impacts from bubbles outweigh the negative impacts, but the reverse holds true for higher levels of risk aversion or when the underinvestment problem is less severe.

\footnotetext{
${ }^{19}$ The model statistics for $\mu_{t+1}^{c}$ shown in Table 4 differ slightly from those shown earlier in Tables 2 and 3 because the Table 4 statistics are averaged over 5000 simulations as part of the welfare computation, as described in Appendix E.
} 
Table 4: Moments that Influence Welfare Computation

\begin{tabular}{clccc}
\hline \hline \multirow{2}{*}{$\alpha$} & & \multicolumn{3}{c}{$\theta=0.4$} \\
\cline { 3 - 5 } & Statistic & $\begin{array}{c}\text { Deterministic } \\
\text { Model }\end{array}$ & $\begin{array}{c}\text { Rational } \\
\text { Model }\end{array}$ & $\begin{array}{c}\text { Bubble } \\
\text { Model }\end{array}$ \\
\hline \multirow{2}{*}{0.5} & Mean $i_{t} / k_{t}$ & 8.33 & 8.41 & 8.63 \\
& Std. Dev. $i_{t} / k_{t}$ & 0 & 0.95 & 2.31 \\
& Mean $\mu_{t+1}^{c}$ & 2.13 & 2.15 & 2.12 \\
& Std. Dev. $\mu_{t+1}^{c}$ & 0 & 5.54 & 3.47 \\
\hline \multirow{4}{*}{1.5} & Mean $i_{t} / k_{t}$ & 8.23 & 8.32 & 8.60 \\
& Std. Dev. $i_{t} / k_{t}$ & 0 & 1.08 & 2.29 \\
& Mean $\mu_{t+1}^{c}$ & 2.05 & 2.06 & 2.11 \\
& Std. Dev. $\mu_{t+1}^{c}$ & 0 & 5.29 & 3.48 \\
\hline \multirow{4}{*}{2.5} & Mean $i_{t} / k_{t}$ & 8.03 & 8.21 & 8.59 \\
& Std. Dev. $i_{t} / k_{t}$ & 0 & 1.13 & 2.28 \\
& Mean $\mu_{t+1}^{c}$ & 1.87 & 1.95 & 2.10 \\
& Std. Dev. $\mu_{t+1}^{c}$ & 0 & 5.18 & 3.48 \\
\hline
\end{tabular}

Note: In percent, averaged over 5000 simulations of 2500 periods each.

Table 5 summarizes the welfare cost of speculative bubbles relative to the rational model with identical parameter values. The table shows that bubbles can improve welfare if risk aversion is very low $(\alpha=0.5)$ and the underinvestment problem is severe $(\theta=0.4)$. Higher levels of risk aversion cause the welfare cost of bubbles to increase rapidly when $\theta=0.4$, but the welfare costs decline a bit with risk aversion when $\theta=1$. When $\theta=1$, there is no underinvestment problem in the economy. In this case, the bubble model's higher mean value of $i_{t} / k_{t}$ represents a misallocation of resources. The bubble model's excess volatility in $i_{t} / k_{t}$ continues to waste resources via the convex capital adjustment costs. These negative welfare impacts must be weighed against the rational model's higher consumption growth volatility, with the latter taking on greater significance for welfare at higher degrees of risk aversion. Consequently, as risk aversion rises with $\theta=1$, the welfare cost of bubbles relative to the rational model exhibits a declining tendency over the range $0.5 \leq \alpha \leq 2.5$.

Table 5: Welfare Cost of Speculative Bubbles

\begin{tabular}{cccc}
\hline \hline$\alpha$ & $\theta=0.4$ & $\theta=0.6$ & $\theta=1.0$ \\
\hline 0.5 & -0.93 & 1.07 & 3.27 \\
1.0 & 0.41 & 1.68 & 2.74 \\
1.5 & 1.32 & 2.15 & 2.42 \\
2.0 & 2.06 & 2.57 & 2.23 \\
2.5 & 2.75 & 2.98 & 2.13 \\
\hline
\end{tabular}

Note: In percent of per-period consumption.

The results in Table 5 reflect a complex combination of effects that involve shifts in the endogenous trend growth rate of consumption, shifts in the volatility of consumption growth, and shifts in the level of consumption (as reflected in average initial consumption and the mean $i_{t} / k_{t}$ ratio). In an effort to gauge the magnitude of the effects coming from the endogenous 
growth feature, I replace $h_{t}=K_{t}$ in the production function (3) with the specification $h_{t}=$ $k_{0} \exp (\mu t)$, where $\mu=0.0203$ is an exogenous trend growth rate imposed on both the rational and bubble versions of the model. For simplicity, I employ the same decision rules for $x_{t}$ as in the original versions of each model. ${ }^{20}$ For the baseline calibration with $\theta=0.4$ and $\alpha=1.5$, the welfare cost of speculative bubbles under exogenous growth is 0.30 percent-less than one-fourth of the 1.32 percent cost obtained under endogenous growth. This result is not surprising; it is well-known since Lucas (1987) that the welfare cost of cyclical fluctuations in standard models is generally small in the absence of long-run growth effects. Notwithstanding this result, the U.S. data plotted in Figure 3 supports the notion that bubbles can influence trend growth, as captured by the original model.

Table 6 summarizes the welfare cost of business cycles in the bubble model relative to a deterministic model with identical parameter values. I focus on the welfare cost of business cycles in the bubble model (as opposed to the rational model) because, by construction, the bubble model matches the empirical targets listed in Table 1, and hence is a more realistic representation of the U.S. economy for the chosen parameter values. The welfare comparison between the bubble model and the deterministic model shown in Table 6 can be interpreted as a more extreme experiment in the effects removing fluctuations relative to that shown in Table 5. As before, the welfare costs increase rapidly with risk aversion when $\theta=0.4$. Now however, the welfare costs are also increasing with risk aversion when $\theta=1$, in contrast to the pattern in Table 5 . In this case, the bubble model is being compared to an alternative where consumption growth is constant, whereas in Table 5 , the bubble model is being compared to an alternative where consumption growth is more volatile.

Referring back to Table 4 , when $\alpha=0.5$ and $\theta=0.4$, the deterministic model exhibits a lower mean $i_{t} / k_{t}$ ratio than the bubble model (8.33\% versus $8.63 \%$ ) - a feature that is particularly costly when $\theta=0.4$. Business cycles (which include intermittent bubble episodes) serve to direct more resources to investment on average and thereby help to address the underinvestment problem. For this reason, and because risk aversion is low, business cycle fluctuations in the bubble model serve to increase welfare by $2.42 \%$. But as risk aversion increases, the agent increasingly dislikes consumption growth volatility and the negative effects of fluctuations dominate the positive effects, producing large welfare losses.

\footnotetext{
${ }^{20}$ The re-optimized decision rules for $x_{t}$ would depend not only on the technology shock $z_{t}$, but also on the normalized capital stock, defined as $k_{t} / \exp (\mu t)$.
} 
Table 6: Welfare Cost of Business Cycles in Bubble Model

\begin{tabular}{cccc}
\hline \hline$\alpha$ & $\theta=0.4$ & $\theta=0.6$ & $\theta=1.0$ \\
\hline 0.5 & -2.42 & -0.01 & 2.16 \\
1.0 & 0.42 & 1.68 & 2.75 \\
1.5 & 2.28 & 3.11 & 3.46 \\
2.0 & 3.75 & 4.41 & 4.24 \\
2.5 & 5.02 & 5.65 & 5.09 \\
\hline
\end{tabular}

Note: In percent of per-period consumption.

Overall, the main message from the welfare analysis is that technology-driven bubbles and the associated business cycle fluctuations can be very costly for typical parameter settings. When the risk aversion coefficient is $\alpha=1.5$, the welfare costs in Tables 5 and 6 range from a low of $1.32 \%$ to a high $3.46 \%$.

Barlevy (2004) estimates that eliminating business cycles can yield welfare gains of around 7 percent of per-period consumption in an endogenous growth model with logarithmic utility $(\alpha=1)$ and no productive externality $(\theta=1)$. Barlevy's rational model is calibrated to match post-World War II data, whereas the bubble model considered here is calibrated to match long-run data prior to the year 1900. Interestingly, the welfare costs of business cycles in the bubble model with $\theta=1$ are not too far from Barlevy's results, despite differences in the capital adjustment cost formulation and the calibration methodology. Qualitatively, the results presented in Table 6 are consistent with Barlevy's finding that the welfare cost of business cycles can be large when fluctuations influence trend growth.

\section{Concluding Remarks}

"Nowhere does history indulge in repetitions so often or so uniformly as in Wall Street," observed legendary speculator Jesse Livermore way back in the year $1923{ }^{21}$ History has proven him right. The dramatic run-up and crash of the U.S. stock market in the late 1920s was followed decades later by twin bubbles and crashes in Japanese real estate and stocks during the late 1980s and early 1990s. These episodes were later followed by the U.S. technology stock mania of the late 1990s, which ended abruptly in March 2000. Most recently, a global housing bubble during the mid-2000s nearly brought down the world's financial system when, like all preceding bubbles, it ultimately burst.

History tells us that periods of major technological innovation are often accompanied by speculative bubbles. Excessive run-ups in asset prices can have important consequences for the economy because mispriced assets imply a shift in resources relative to a bubble-free economy. Innovations to technology are also considered by many economists to be an important driving force for ordinary business cycles.

\footnotetext{
${ }^{21}$ From Livermore's thinly-disguised biography by E. Lefevére (1923, p. 180).
} 
This paper developed a real business cycle model in which a bubble component in the equity price generates excess volatility in response to observed technology shocks. The setup can be described as "near-rational" because the bubble law of motion approximately satisfies a period-by-period no-arbitrage condition. The bubble model outperformed the rational model in capturing several features of long-run U.S. data, including the moments of asset pricing variables and the relative volatilities of output, investment, and consumption growth rates.

Interestingly, even from the narrow perspective of this simple theoretical model, it remains an open question whether the costs of speculative bubbles outweigh the possible benefits to society. According to the model, risk aversion must be low and the underinvestment problem must be severe for bubbles to be welfare-improving. But for typical parameter settings, the model showed that the welfare cost of bubbles is large.

It should be noted, of course, that the model abstracts from numerous real-world issues that would affect investors' welfare. One noteworthy example is financial fraud. Throughout history, speculative bubbles have usually coincided with outbreaks of fraud and scandal, followed by calls for more government regulation once the bubble has burst. ${ }^{22}$ Recent bubble episodes are no different.

\footnotetext{
${ }^{22}$ For a comprehensive historical review, see Gerding (2006).
} 


\section{A Appendix: Rational Solution}

This appendix provides the proof of Proposition 1. Taking logarithms of both sides of the transformed first-order condition (15) and then applying a first-order Taylor series approximation to each side yields equation (16). The Taylor-series coefficients are given by

$$
\begin{aligned}
a_{0} & =\frac{\widetilde{x}^{1-\lambda \phi}}{(1+\lambda \widetilde{x})^{(1-\lambda) \phi}}, \\
a_{1} & =1-\frac{\phi \lambda(1+\widetilde{x})}{1+\lambda \widetilde{x}}, \\
b_{0} & =\widetilde{\beta}\left[\frac{\theta+\widetilde{x}(1-\lambda+\lambda \theta)}{(1+\lambda \widetilde{x})^{\phi}}\right], \\
b_{1} & =\frac{\widetilde{x}(1-\lambda+\lambda \theta)}{\theta+\widetilde{x}(1-\lambda+\lambda \theta)}-\frac{\phi \lambda \widetilde{x}}{1+\lambda \widetilde{x}},
\end{aligned}
$$

where $\widetilde{x}=\exp \left\{E\left[\log \left(x_{t}\right)\right]\right\}$ is the approximation point and $\widetilde{\beta} \equiv \beta\left[B(A \lambda)^{\lambda}\right]^{\phi}$.

The conjectured form of the rational solution $x_{t+1}=\widetilde{x} \exp \left(\gamma z_{t+1}\right)$ is substituted into the right-side of (16). After evaluating the conditional expectation and then collecting terms, we have:

$$
x_{t}=\underbrace{\widetilde{x}\left[\frac{b_{0}}{a_{0}}\right]^{1 / a_{1}} \exp \left[\frac{\left(\gamma b_{1}+\phi\right)^{2} \sigma_{\epsilon}^{2}}{2 a_{1}}\right]}_{\widetilde{x}} \exp [\underbrace{\frac{\rho\left(\gamma b_{1}+\phi\right)-\phi(1-\lambda)}{a_{1}}}_{\gamma} z_{t}],
$$

which shows that the conjectured form is correct. Solving for the undetermined coefficient $\gamma$ yields

$$
\gamma=\frac{\phi[\rho-(1-\lambda)]}{a_{1}-\rho b_{1}}
$$

where $a_{1}$ and $b_{1}$ both depend on $\widetilde{x}$ from (A.2) and (A.4).

The undetermined coefficient $\widetilde{x}$ solves the following nonlinear equation

$$
\widetilde{x}=\frac{\theta \beta \exp \left[\phi \widetilde{\mu}+\left(\gamma b_{1}+\phi\right)^{2} \sigma_{\epsilon}^{2} / 2\right]}{1-\beta(1-\lambda+\lambda \theta) \exp \left[\phi \widetilde{\mu}+\left(\gamma b_{1}+\phi\right)^{2} \sigma_{\epsilon}^{2} / 2\right]},
$$

where $\widetilde{\mu}$ depends on $\widetilde{x}$ as shown below:

$$
\exp (\widetilde{\mu})=B A^{\lambda}\left[\frac{\lambda \widetilde{x}}{1+\lambda \widetilde{x}}\right]^{\lambda} .
$$

Comparing (A.8) to equation (14) shows that $\widetilde{\mu}$ represents the endogenous trend growth rate of consumption in the rational model. Given a set of parameter values, equations (A.7) and (A.8) are solved simultaneously for $\widetilde{x}$ and $\widetilde{\mu}$. Equation (A.6) is then used to compute $\gamma$. 


\section{B Appendix: Fundamental Solution in Bubble Economy}

This appendix provides the proof of Proposition 2. Taking logarithms of both sides of the transformed first-order condition (23) and then applying a first-order Taylor series approximation to each side yields equation (24). The Taylor series coefficients $a_{0}^{\mathrm{f}}, a_{1}^{\mathrm{f}}, b_{0}^{\mathrm{f}}$, and $b_{1}^{\mathrm{f}}$ take the same form as equations (A.1) through (A.4), but $\widetilde{x}$ is now replaced by $\widetilde{x}^{\mathrm{f}}$ since $\widetilde{x}^{\mathrm{b}}=0$. The Taylor-series coefficients $a_{2}^{\mathrm{f}}$ and $b_{2}^{\mathrm{f}}$ are given by

$$
\begin{aligned}
& a_{2}^{\mathrm{f}}=\phi\left(1-\lambda-\lambda \gamma^{\mathrm{b}}\right)-\frac{\phi(1-\lambda) \lambda \widetilde{x}^{\mathrm{f}} \gamma^{\mathrm{b}}}{1+\lambda \widetilde{x}^{\mathrm{f}}} \\
& b_{2}^{\mathrm{f}}=\frac{\phi\left[1+\lambda \widetilde{x}^{\mathrm{f}}\left(1-\gamma^{\mathrm{b}}\right)\right]}{1+\lambda \widetilde{x}^{\mathrm{f}}}-\frac{\lambda(1-\theta) \widetilde{x}^{\mathrm{f}} \gamma^{\mathrm{b}}}{\theta+\widetilde{x}^{\mathrm{f}}(1-\lambda+\lambda \theta)},
\end{aligned}
$$

where $\widetilde{x}^{\mathrm{f}}=\exp \left\{E\left[\log \left(x_{t}^{\mathrm{f}}\right)\right]\right\}=\exp \left\{E\left[\log \left(x_{t}\right)\right]\right\}$ is the approximation point. Notice that the bubble law of motion influences the fundamental solution via the presence of $\gamma^{\mathrm{b}}$ in the expressions for $a_{2}^{\mathrm{f}}$ and $b_{2}^{\mathrm{f}}$.

The conjectured form of the fundamental solution $x_{t+1}^{\mathrm{f}}=\widetilde{x}^{\mathrm{f}} \exp \left(\gamma^{\mathrm{f}} z_{t+1}\right)$ is substituted into the right-side of (24). After evaluating the conditional expectation and then collecting terms, we have:

$$
x_{t}^{\mathrm{f}}=\underbrace{\widetilde{x}^{\mathrm{f}}\left[\frac{b_{0}^{\mathrm{f}}}{a_{0}^{\mathrm{f}}}\right]^{1 / a_{1}^{\mathrm{f}}} \exp \left[\frac{\left(\gamma^{\mathrm{f}} b_{1}^{\mathrm{f}}+b_{2}^{\mathrm{f}}\right)^{2} \sigma_{\epsilon}^{2}}{2 a_{1}^{\mathrm{f}}}\right]}_{\widetilde{x}^{\mathrm{f}}} \exp [\underbrace{\frac{\rho\left(\gamma^{\mathrm{f}} b_{1}^{\mathrm{f}}+b_{2}^{\mathrm{f}}\right)-a_{2}^{\mathrm{f}}}{a_{1}^{\mathrm{f}}}}_{\gamma^{\mathrm{f}}} z_{t}],
$$

which shows that the conjectured form is correct. Solving for the undetermined coefficient $\gamma^{\mathrm{f}}$ yields

$$
\gamma^{\mathrm{f}}=\frac{\rho b_{2}^{\mathrm{f}}-a_{2}^{\mathrm{f}}}{a_{1}^{\mathrm{f}}-\rho b_{1}^{\mathrm{f}}}
$$

The undetermined coefficient $\widetilde{x}^{\mathrm{f}}$ solves the following nonlinear equation

$$
\widetilde{x}^{\mathrm{f}}=\frac{\theta \beta \exp \left[\phi \widetilde{\mu}^{\mathrm{f}}+\left(\gamma^{\mathrm{f}} b_{1}^{\mathrm{f}}+b_{2}^{\mathrm{f}}\right)^{2} \sigma_{\epsilon}^{2} / 2\right]}{1-\beta(1-\lambda+\lambda \theta) \exp \left[\phi \widetilde{\mu}^{\mathrm{f}}+\left(\gamma^{\mathrm{f}} b_{1}^{\mathrm{f}}+b_{2}^{\mathrm{f}}\right)^{2} \sigma_{\epsilon}^{2} / 2\right]},
$$

where $\widetilde{\mu}^{\mathrm{f}}$ depends on $\widetilde{x}^{\mathrm{f}}$ as shown below:

$$
\exp \left(\widetilde{\mu}^{\mathrm{f}}\right)=B A^{\lambda}\left[\frac{\lambda \widetilde{x}^{\mathrm{f}}}{1+\lambda \widetilde{x}^{\mathrm{f}}}\right]^{\lambda}
$$

In the above equation, $\widetilde{\mu}^{\mathrm{f}}$ represents the endogenous trend growth rate of consumption in the bubble economy. Given a set of parameter values and a value for $\gamma^{\mathrm{b}}$, equations (B.5) and (B.6) are solved simultaneously for $\widetilde{x}^{\mathrm{f}}$ and $\widetilde{\mu}^{\mathrm{f}}$. Equation (B.4) is then used to compute $\gamma^{\mathrm{f}}$. 


\section{Appendix: Approximate Moments for Calibration}

Starting from equation (26), a Taylor series approximation for the total price-dividend ratio in the bubble economy is given by

$$
\begin{aligned}
& \frac{p_{t}}{d_{t}}=\frac{p_{t}^{\mathrm{f}}+p_{t}^{\mathrm{b}}}{d_{t}}=n_{0}\left[\frac{x_{t}}{\widetilde{x}^{\mathrm{f}}}\right]^{n_{1}}, \\
& \text { where } \quad n_{0}=\frac{\widetilde{x}^{\mathrm{f}}}{\theta-(1-\theta) \lambda \widetilde{x}^{\mathrm{f}}}, \quad n_{1}=\frac{\theta}{\theta-(1-\theta) \lambda \widetilde{x}^{\mathrm{f}}},
\end{aligned}
$$

and $\widetilde{x}^{\mathrm{f}}=\exp \left\{E\left[\log \left(x_{t}^{\mathrm{f}}\right)\right]\right\}=\exp \left\{E\left[\log \left(x_{t}\right)\right]\right\}$, with $\widetilde{x}^{\mathrm{b}}=0$. The above expression implies the following unconditional moments:

$$
\begin{aligned}
E\left[\log \left(p_{t} / d_{t}\right)\right] & =\log \left(n_{0}\right), \\
\operatorname{Var}\left[\log \left(p_{t} / d_{t}\right)\right] & =\left(n_{1}\right)^{2} \operatorname{Var}\left[\log \left(x_{t}\right)\right], \\
& =\left(n_{1}\right)^{2}\left(\gamma^{\mathrm{f}}+\gamma^{\mathrm{b}}\right)^{2} \operatorname{Var}\left(z_{t}\right), \\
\operatorname{Corr}\left[\log \left(p_{t} / d_{t}\right), \log \left(p_{t-1} / d_{t-1}\right)\right] & =\operatorname{Corr}\left[\log \left(x_{t}\right), \log \left(x_{t-1}\right)\right], \\
& =\operatorname{Corr}\left[z_{t}, z_{t-1}\right], \\
& =\rho .
\end{aligned}
$$

Given equations (C.2) and (C.3), the unconditional mean and variance of $p_{t} / d_{t}$ can be computed by making use of the properties of the log-normal distribution. ${ }^{23}$

Starting from equation (14) which carries over to the bubble economy with $x_{t}=x_{t}^{\mathrm{f}}+x_{t}^{\mathrm{b}}$, a Taylor-series approximation for consumption growth is given by

$$
\begin{aligned}
& \frac{c_{t+1}}{c_{t}}=\exp \left(\widetilde{\mu}^{\mathrm{f}}\right)\left[\frac{x_{t+1}}{\widetilde{x}^{\mathrm{f}}}\right]^{h_{1}}\left[\frac{x_{t}}{\widetilde{x}^{\mathrm{f}}}\right]^{h_{2}} \exp \left[z_{t+1}-(1-\lambda) z_{t}\right], \\
& \text { where } \quad h_{1}=\frac{-\lambda \widetilde{x}^{\mathrm{f}}}{1+\lambda \widetilde{x}^{\mathrm{f}}}, \quad h_{2}=\frac{\lambda\left(1+\widetilde{x}^{\mathrm{f}}\right)}{1+\lambda \widetilde{x}^{\mathrm{f}}},
\end{aligned}
$$

and $\exp \left(\widetilde{\mu}^{\mathrm{f}}\right)$ is given by equation (B.6). Given the solution for $x_{t}$ in equation (25), the above expression implies the following results

$$
\begin{aligned}
\log \left(c_{t+1} / c_{t}\right)= & \widetilde{\mu}^{\mathrm{f}}+\left[h_{1}\left(\gamma^{\mathrm{f}}+\gamma^{\mathrm{b}}\right)+1\right] z_{t+1}+\left[h_{2}\left(\gamma^{\mathrm{f}}+\gamma^{\mathrm{b}}\right)-1+\lambda\right] z_{t}, \\
E\left[\log \left(c_{t+1} / c_{t}\right)\right]= & \widetilde{\mu}^{\mathrm{f}} \\
\operatorname{Var}\left[\log \left(c_{t+1} / c_{t}\right)\right]= & \left\{\left[h_{1}\left(\gamma^{\mathrm{f}}+\gamma^{\mathrm{b}}\right)+1\right]^{2}+\left[h_{2}\left(\gamma^{\mathrm{f}}+\gamma^{\mathrm{b}}\right)-1+\lambda\right]^{2}+\right. \\
& \left.+2 \rho\left[h_{1}\left(\gamma^{\mathrm{f}}+\gamma^{\mathrm{b}}\right)+1\right]\left[h_{2}\left(\gamma^{\mathrm{f}}+\gamma^{\mathrm{b}}\right)-1+\lambda\right]\right\} \operatorname{Var}\left(z_{t}\right) .
\end{aligned}
$$

\footnotetext{
${ }^{23}$ If a random variable $w_{t}$ is $\log$-normally distributed, then $E\left(w_{t}\right)=\exp \left\{E\left[\log \left(w_{t}\right)\right]+\frac{1}{2} \operatorname{Var}\left[\log \left(w_{t}\right)\right]\right\}$ and $\operatorname{Var}\left(w_{t}\right)=E\left(w_{t}\right)^{2}\left\{\exp \left(\operatorname{Var}\left[\log \left(w_{t}\right)\right]\right)-1\right\}$.
} 
In the nonlinear model simulations (described below in Appendix D), the moments of the price-dividend ratio and consumption growth in the bubble model can differ from those predicted by the approximate moment formulas, depending on the calibration. A process of trial and error is used to select the parameter values used for the nonlinear model simulations. The parameter values implied by the approximate moment formulas provide a good starting point for the trial and error calibration process.

\section{Appendix: Model Simulations}

The simulation algorithm is governed by the following system of nonlinear stochastic difference equations:

$$
\begin{aligned}
\frac{\left(x_{t}^{\mathrm{f}}\right)^{1-\lambda \phi} \exp \left[\phi\left(1-\lambda-\lambda \gamma^{\mathrm{b}}\right) z_{t}\right]}{\left[1+\lambda x_{t}^{\mathrm{f}} \exp \left(\gamma^{\mathrm{b}} z_{t}\right)\right]^{(1-\lambda) \phi}} & =b_{0}^{\mathrm{f}} \exp \left[\rho\left(\gamma^{\mathrm{f}} b_{1}^{\mathrm{f}}+b_{2}^{\mathrm{f}}\right) z_{t}+\frac{1}{2}\left(\gamma^{\mathrm{f}} b_{1}^{\mathrm{f}}+b_{2}^{\mathrm{f}}\right)^{2} \sigma_{\epsilon}^{2}\right] \\
x_{t}^{\mathrm{b}} & =x_{t}^{\mathrm{f}}\left[\exp \left(\gamma^{\mathrm{b}} z_{t}\right)-1\right] \\
x_{t} & =x_{t}^{\mathrm{f}}+x_{t}^{\mathrm{b}}
\end{aligned}
$$

where $z_{t}$ is governed by the stochastic process (4). Equation (D.1) is the fundamental noarbitrage condition (23) where the right side shows the agent's conditional forecast computed using the power function approximation from (24) together with the approximate fundamental solution from Proposition 2. Given the conditional forecast and the current observed value of $z_{t}$, the left side of (D.1) is solved for $x_{t}^{\mathrm{f}}$ each period using a nonlinear equation solver. Given $x_{t}^{\mathrm{f}}$ and $z_{t}$, the bubble law of motion (D.2) is used to compute $x_{t}^{\mathrm{b}}$ which in turn gives $x_{t}$ from (D.3). Given $x_{t}$, equations (10) through (12) are used to compute the allocations in the bubble model where output is given by $y_{t}=A \exp \left(z_{t}\right) k_{t}$. The capital stock evolves according to equation (5).

The initial condition in the simulations is the deterministic steady state which is the same for both the bubble model and the rational model. The steady-state price-consumption ratio is denoted by $\bar{x}$. Steady-state consumption growth is denoted by $\bar{\mu}$. The values of $\bar{x}$ and $\bar{\mu}$ solve the following system of nonlinear equations

$$
\begin{aligned}
\bar{x} & =\frac{\theta \beta \exp (\phi \bar{\mu})}{1-\beta(1-\lambda+\lambda \theta) \exp (\phi \bar{\mu})}, \\
\exp (\bar{\mu}) & =B A^{\lambda}\left[\frac{\lambda \bar{x}}{1+\lambda \bar{x}}\right]^{\lambda} .
\end{aligned}
$$

\section{E Appendix: Welfare Cost Computation}

This appendix describes the procedure for computing the welfare costs presented in Tables 5 , 6 , and 7 .

\section{E.1 Welfare Cost of Speculative Bubbles}

Average lifetime utility can be written as

$$
V_{i}=\frac{-1}{\phi(1-\beta)}+E \sum_{t=0}^{\infty} \beta^{t} \frac{\left(c_{i, t}\right)^{\phi}}{\phi}, \quad \phi \equiv 1-\alpha,
$$


where $i=1,2$ for the rational model and the bubble model, respectively. From equation (10) we have $c_{i, t}=y_{i, t} /\left(1+\lambda x_{i, t}\right)$ where $x_{i, t}$ is computed using the nonlinear algorithm described in Appendix D. The unconditional mean $E$ is approximated by the average over 5000 simulations, each 2500 periods in length, after which the results are not changed. The initial consumption levels at $t=0$ are stochastic variables. Each simulation starts at $t=-1$ with $y_{i, t}=1$, such that $c_{i, t}=1 /(1+\lambda \bar{x})$, where $\bar{x}$ is the steady-state price-consumption ratio from equation (D.7). Note that the rational model and the bubble model share the same steady state.

The welfare cost of speculative bubbles is the constant percentage amount by which $c_{2, t}$ must be increased in the bubble model in order to make average lifetime utility equal to that in the rational model. Specifically, I solve for $\tau$ such that

$$
\begin{aligned}
V_{1} & =\frac{-1}{\phi(1-\beta)}+E \sum_{t=0}^{\infty} \beta^{t} \frac{\left[c_{2, t}(1+\tau)\right]^{\phi}}{\phi} . \\
& =\frac{-1}{\phi(1-\beta)}+(1+\tau)^{\phi}\left[V_{2}+\frac{1}{\phi(1-\beta)}\right]
\end{aligned}
$$

which yields the result

$$
\tau=\left[\frac{\phi(1-\beta) V_{1}+1}{\phi(1-\beta) V_{2}+1}\right]^{\frac{1}{\phi}}-1 .
$$

In the case of $\log$ utility $(\phi=0)$, equation (E.3) becomes $\tau=\exp \left[\left(V_{1}-V_{2}\right)(1-\beta)\right]-1$.

\section{E.2 Welfare Cost of Business Cycles}

Lifetime utility in the deterministic model is computed from equation (E.1) with $i=0$ and is denoted by $V_{0}$. The welfare cost of business cycles in the bubble model is the constant percentage amount by which $c_{2, t}$ must be increased in order to make $V_{2}$ equal to $V_{0}$. The deterministic simulation starts at $t=-1$ with $y_{0, t}=1$, such that $c_{0, t}=1 /(1+\lambda \bar{x})$, where $\bar{x}$ is given by equation (D.4). Deterministic consumption evolves according to the law of motion $c_{0, t}=c_{0, t-1} \exp (\bar{\mu})$, where $\bar{\mu}$ is given by equation (D.5). Deterministic consumption at $t=0$ will thus differ from average consumption at $t=0$ in the fluctuating models.

Analogous to equation (E.3), the welfare cost of business cycles in the bubble model is given by

$$
\tau=\left[\frac{\phi(1-\beta) V_{0}+1}{\phi(1-\beta) V_{2}+1}\right]^{\frac{1}{\phi}}-1 .
$$

In the case of $\log$ utility, $(\phi=0)$, equation (E.4) becomes $\tau=\exp \left[\left(V_{0}-V_{2}\right)(1-\beta)\right]-1$. 


\section{References.}

Arbarbanell, J.S. and Bernard, V.L. 1992 Tests of analysts' over-reaction/under-reaction to earnings information as an explanation for anomalous stock price behavior. Journal of Finance 47, 1181-1207.

Arrow, K.J., 1962. The economic implications of learning by doing. Review of Economic Studies 29, 155-173.

Barlevy, G., 2004. The cost of business cycles under endogenous growth. American Economic Review 94, 964-990.

Barro, R.J., 1990. The stock market and investment. Review of Financial Studies, 3, 115-131.

Blundell, R. and MaCurdy, T., 1999. Labor supply: A review of alternative approaches. In: Ashenfelter. O., and Card, D., (Eds.), Handbook of Labor Economics, North-Holland: Amsterdam, 1559-1695.

Caballero, R. J., Farhi, E., and Hammour, M.L., 2006. Speculative growth: Hints from the U.S. economy. American Economic Review, 96, 1159-1192.

Caginalp, G., Porter, D., and Smith, V.L., 2000. Overreactions, momentum, liquidity, and price bubbles in laboratory and field asset markets. Journal of Psychology and Financial Markets, 1, 24-48.

Campello, M. and Graham, J., 2012. Do stock prices influence corporate decisions? Evidence from the technology bubble, Journal of Financial Economics, forthcoming.

Cassou, S.P. and Lansing, K.J., 2006. Tax reform with useful public expenditures, Journal of Public Economic Theory 8, 631-676.

Chirinko, R.S. and Schaller, H., 2001. Business fixed investment and 'bubbles': The Japanese case. American Economic Review 91, 663-680.

Cooper, M.J., Dimitrov, O., and Rau, P.R., 2001. A Rose.com by any other name. Journal of Finance 54, 2371-2388.

Daniel, K., Hirshleifer, D., and Subrahmanyam, A. 1998. Investor psychology, and security market under- and overreactions. Journal of Finance 53, 1839-1186

Debondt, W.F.M. Thaler, R., 1985. Does the stock market overeact? Journal of Finance 40, 793-805.

Dupor, B., 2005. Stabilizing non-fundamental asset price movements under discretion and limited information. Journal of Monetary Economics 52, 727-747.

Easterwood, J.C. and Nutt, S.R., 1999. Inefficiency in analysts' earnings forecasts: systematic misreaction or systematic optimism? Journal of Finance 54, 1777-1797.

Froot, K. and Obstfeld, M., 1991. Intrinsic bubbles: the case of stock prices. American Economic Review 81, 1189-1214.

Gerding, E.F., 2006. The next epidemic: Bubbles and the growth and decay of securities regulation. Connecticut Law Review, 383, 393-453.

Gilchrist, S., Himmelberg, C. P., and Huberman, G., 2005. Do stock price bubbles influence corporate investment? Journal of Monetary Economics 52 805-827.

Gordon, R.J., 2000. Does the 'new economy' measure up to the great inventions of the past? Journal of Economic Perspectives 14, 49-74.

Gordon, R.J., 2006. The 1920s and the 1990s in mutual reflection. In: Rhode, P.W., and Toniolo, G., (Eds.), The Global Economy in the 1990s, Cambridge: Cambridge University 
Press, 161-192.

Greenspan, A., 2000. Technology and the economy. Remarks before the Economic Club of New York, New York City, January 13.

Greenspan, A., 2002 Economic volatility. Remarks at a symposium sponsored by the Federal Reserve Bank of Kansas City, Jackson Hole, Wyoming, August 30.

Greenspan, A., 2005. Consumer finance. Remarks at the Federal Reserve System's Fourth Annual Community Affairs Research Conference, Washington, D.C., April 8.

Grossman, G.M. and Yanagawa, N., 1993. Asset bubbles and endogenous growth. Journal of Monetary Economics 31, 3-19.

Hassan, T.A. and Mertens, T.M., 2011. The social cost of near-rational investment: Why we should worry about volatile stock markets. National Bureau of Economic Research, Working Paper 17027.

Hunter, W.C., Kaufman, G.G., and Pomerleano, P., (Eds.), 2003. Asset price bubbles, The implications for monetary, regulatory, and international policies. Cambridge, MA: MIT Press.

Ireland, P.N. and Schuh, S., 2008. Productivity and U.S. macroeconomic performance: Interpreting the past and predicting the future with a two-sector real business cycle model. Review of Economic Dynamics, 11, 473-492.

Jermann, U., 1998. Asset pricing in production economies. Journal of Monetary Economics 41, 257-275.

King, I. and Ferguson, D., 1993. Dynamic inefficiency, endogenous growth, and Ponzi games. Journal of Monetary Economics 32, 79-104.

Lansing, K.J., 2008. Monetary policy and asset prices. Federal Reserve Bank of San Francisco, Economic Letter 2008-34, October 31.

Lansing, K.J., 2009. Time-varying U.S. inflation dynamics and the New Keynesian Phillips curve. Review of Economic Dynamics, 12, 304-326.

Lansing, K.J., 2010. Rational and near-rational bubbles without drift. Economic Journal, $129,1149-1174$.

Lansing, K.J., 2011. Gauging the impact of the Great Recession. Federal Reserve Bank of San Francisco, Economic Letter 2011-21, July 11.

Lansing, K.J., 2011. Asset pricing with concentrated ownership of capital. Federal Reserve Bank of San Francisco, Working Paper 2011-07.

Lansing, K.J. and LeRoy, S.F., 2012. Risk aversion, investor information, and stock market volatility. Federal Reserve Bank of San Francisco, Working Paper 2010-24.

Lefévre, E. 1923. Reminiscences of a stock operator. New York: John Wiley (originally published by G.H. Doran).

LeRoy, S.F. and Porter, R.D., 1981. The present-value relation: Tests based on implied variance bounds. Econometrica 49, 555-577.

Lucas, R.E., 1978. Asset prices in an exchange economy. Econometrica 46, 1429-1445.

Lucas, R.E. 1987. Models of business cycles. Oxford: Basil Blackwell.

MacKay, C. 1841. Extraordinary popular delusions and the madness of crowds. New York: Harmony Books.

McGrattan, E.R. 1998. A defense of $A K$ growth models. Federal Reserve Bank of Minneapolis, Quarterly Review, Fall, 13-27. 
Nicholas. T., 2008. Does innovation cause stock market runups? Evidence from the Great Crash. American Economic Review 98, 1370-1386.

Oliner, S.D. and Sichel, D.E., 2000. The resurgence of growth in the late 1990s: Is information technology the story? Journal of Economic Perspectives 14, 3-22.

Olivier, J., 2000. Growth-enhancing bubbles. International Economic Review 41, 133-151.

Ramey, G. and Ramey, V., 1995. Cross-country evidence on the link between volatility and growth. American Economic Review 85, 1138-1151.

Romer, P., 1986. Increasing returns and long-run growth. Journal of Political Economy 94, 1002-1037.

Saint-Paul G., 1992. Fiscal policy in an endogenous growth model. Quarterly Journal of Economics 107, 1243-1259.

Schwert, G.W., 1989. Why does stock market volatility change over time? Journal of Finance 44, 1115-1153.

Schwert, G.W., 2002. Stock volatility in the new millenium: How wacky is Nasdaq? Journal of Monetary Economics 49, 3-26.

Shiller, R.J., 1981. Do stock prices move too much to be justified by subsequent changes in dividends? American Economic Review 71, 421-436.

Shiller, R.J., 2000. Irrational exuberance. Princeton: Princeton University Press.

Tversky, A. and Kahneman, D., 1974. Judgement under uncertainty: heuristics and biases. Science 185, 1124-1131.

Weil, P. 1990. On the possibility of price decreasing bubbles, Econometrica, 58, 1467-1474.

White, E.N., 2006. Bubbles and busts: The 1990s in the mirror of the 1920s. In: Rhode, P.W., and Toniolo, G., (Eds.), The Global Economy in the 1990s, Cambridge: Cambridge University Press, 193-217. 
Real S\&P 500 Index (in logarithms), 1871-2008

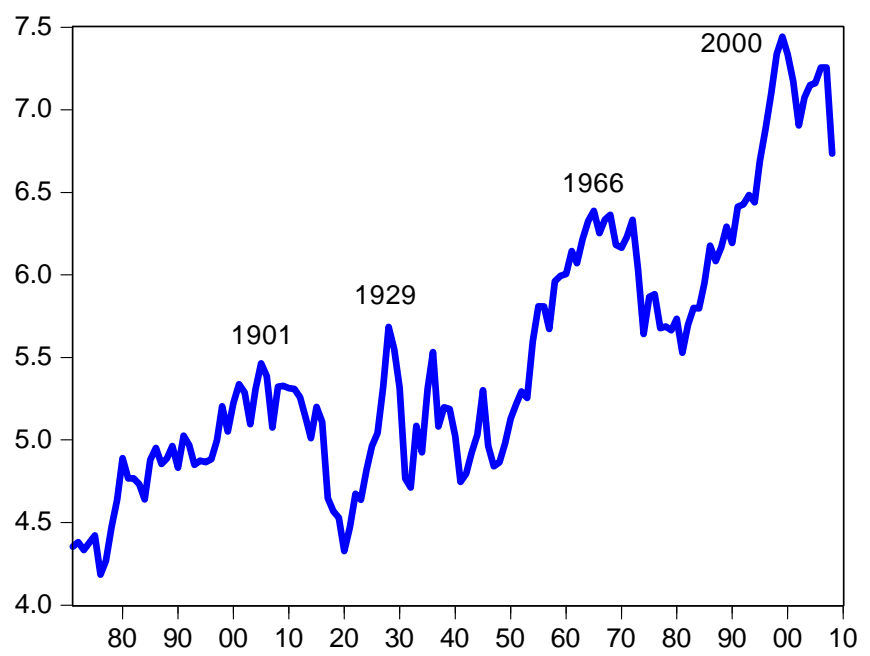

Figure 1: Four major run-ups in U.S. stock prices.

S\&P 500 Index: Price-Dividend Ratio, 1871-2008

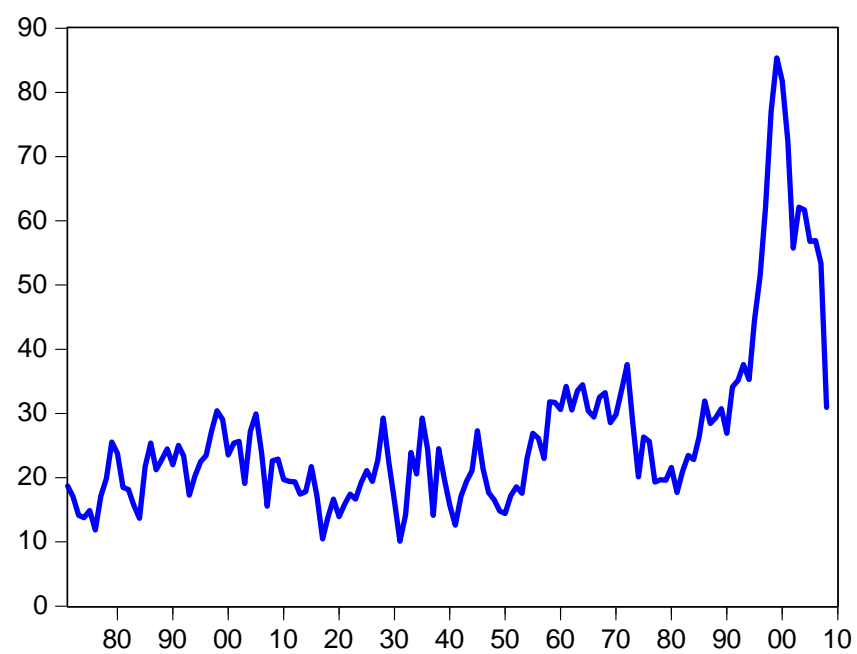

Figure 2: The price-dividend ratio reached unprecedented levels around the year 2000. 


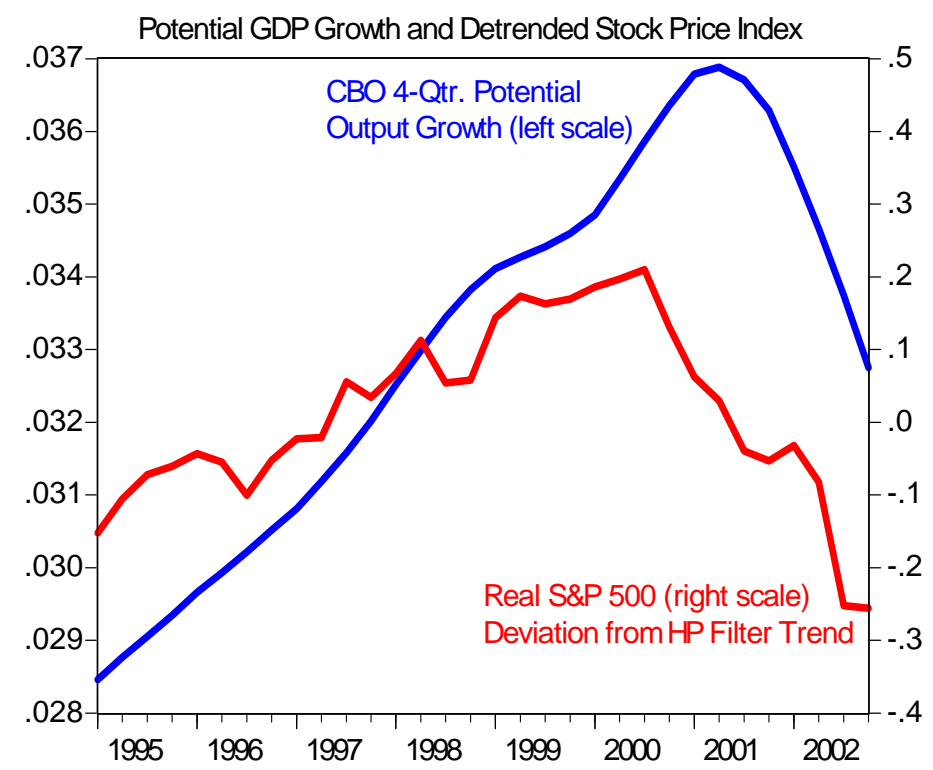

Figure 3: Rise and fall of the "new economy."

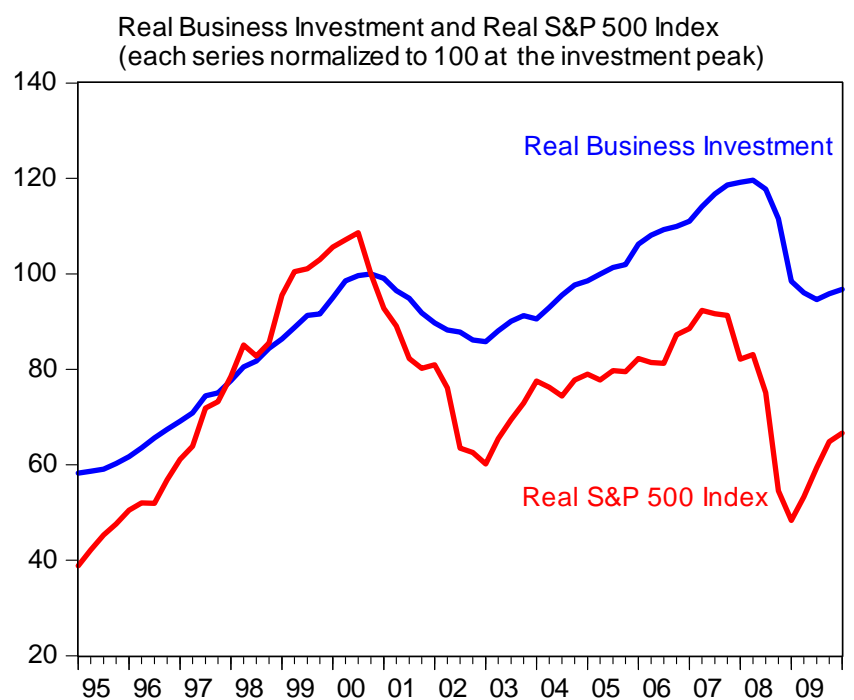

Figure 4: Comovement of business investment and stock prices. 


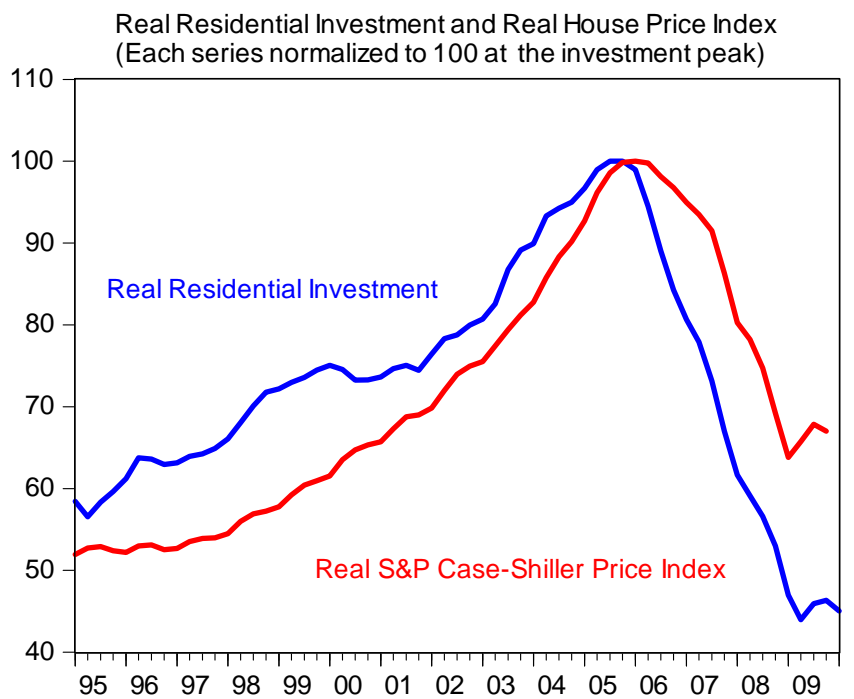

Figure 5: Comovement of residential investment and house prices.

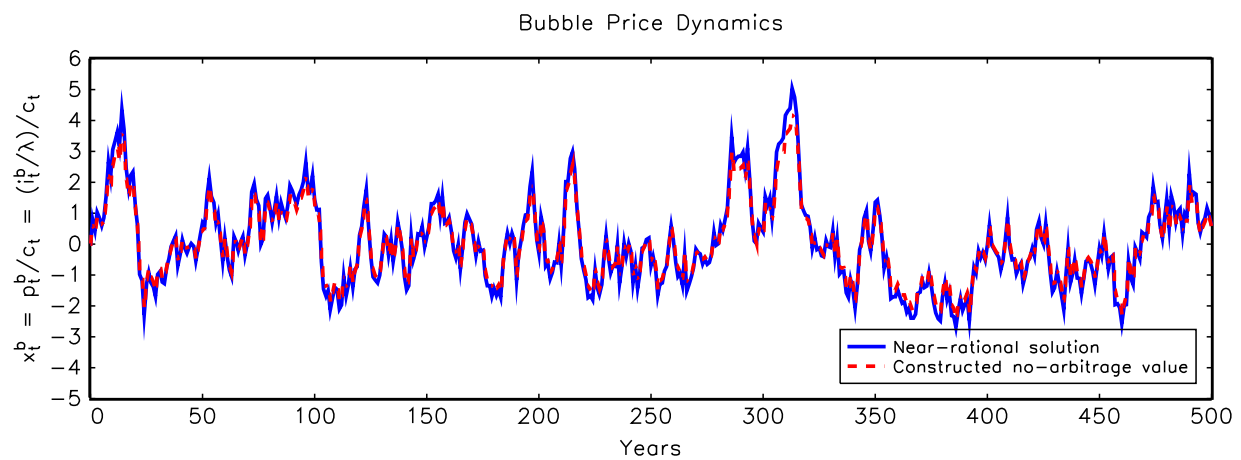

Total Equity Price Dynamics

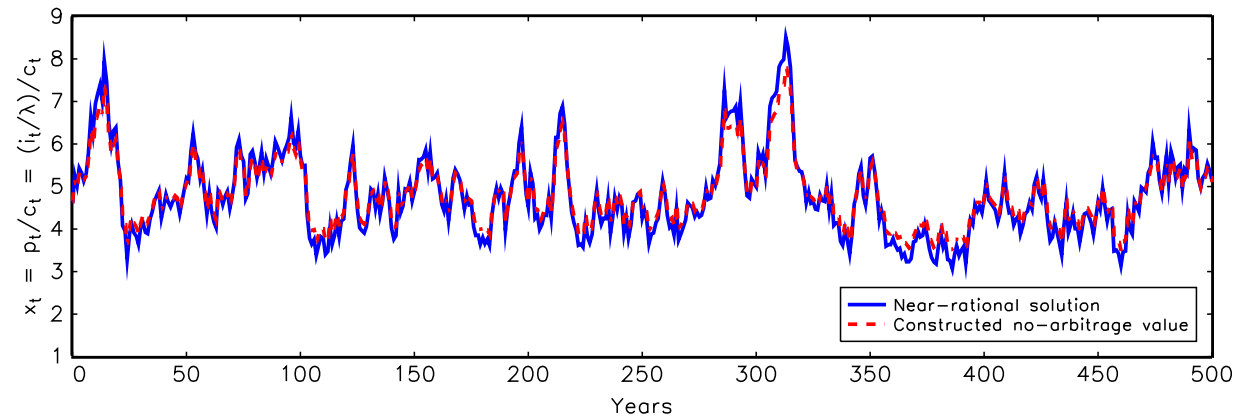

Figure 6: Bubble law of motion approximately satisfies the no-arbitrage condition. 

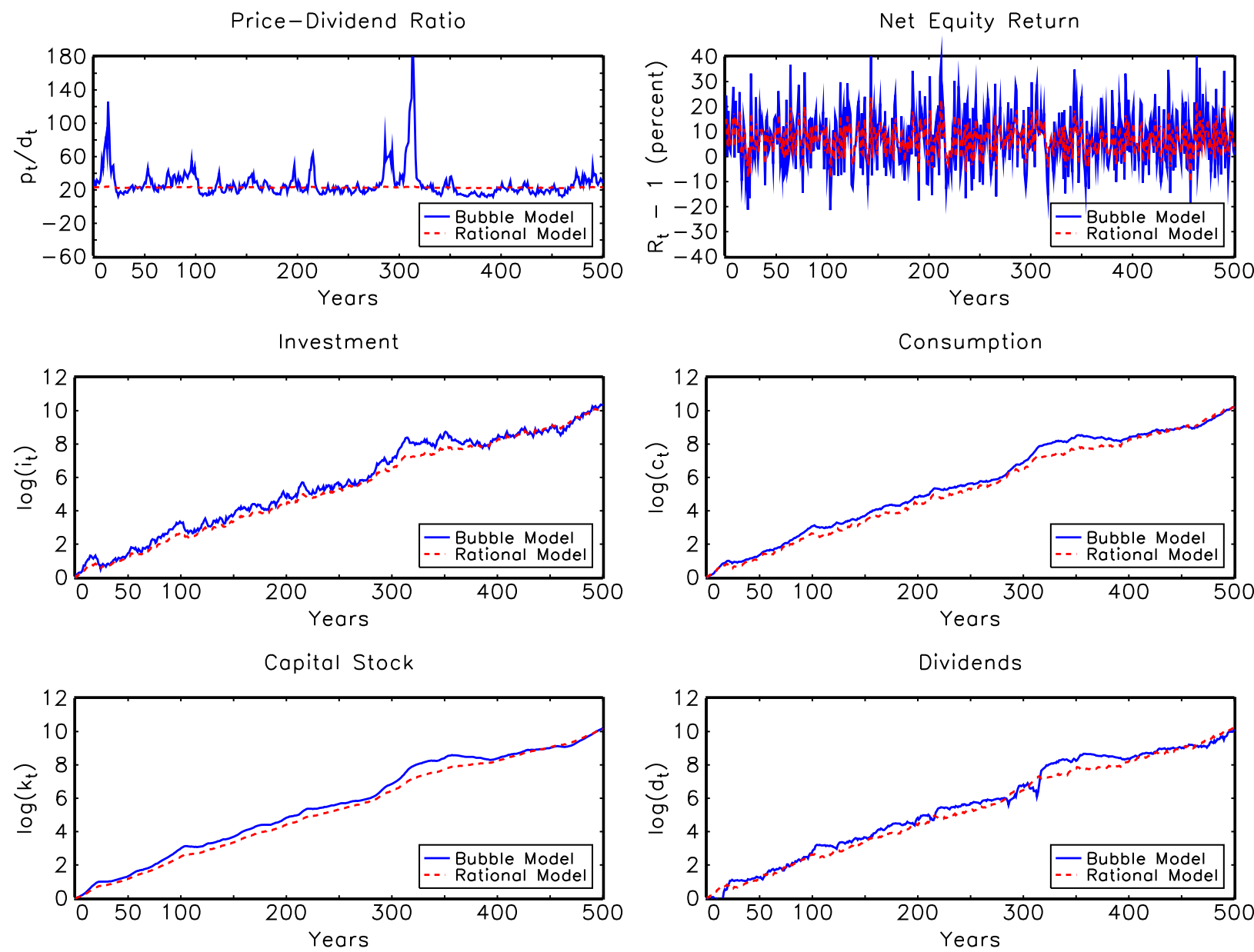

Figure 7: Bubbles coincide with economic booms and excess capital formation. 

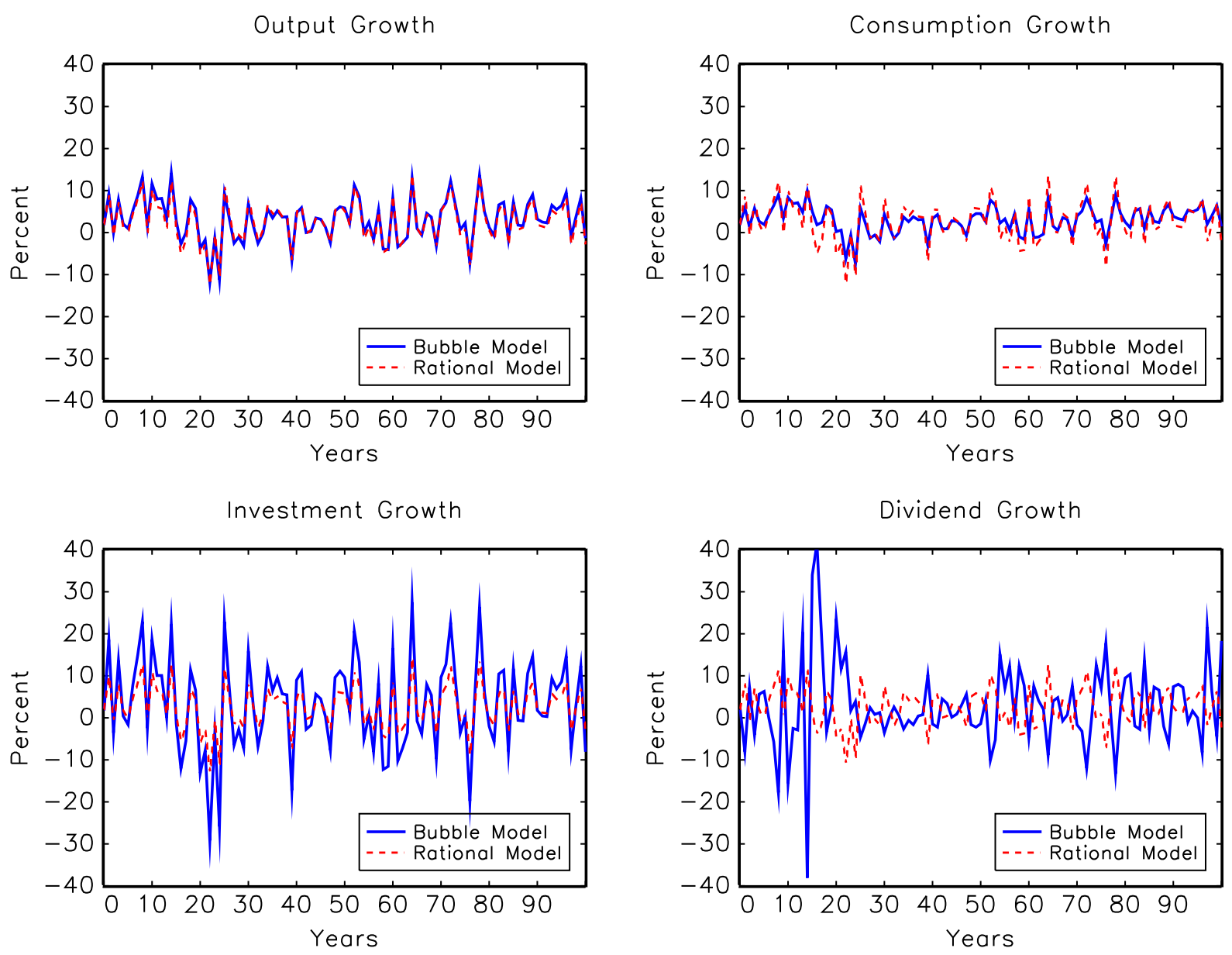

Figure 8: Bubbles magnify investment volatility but reduce consumption volatility. 


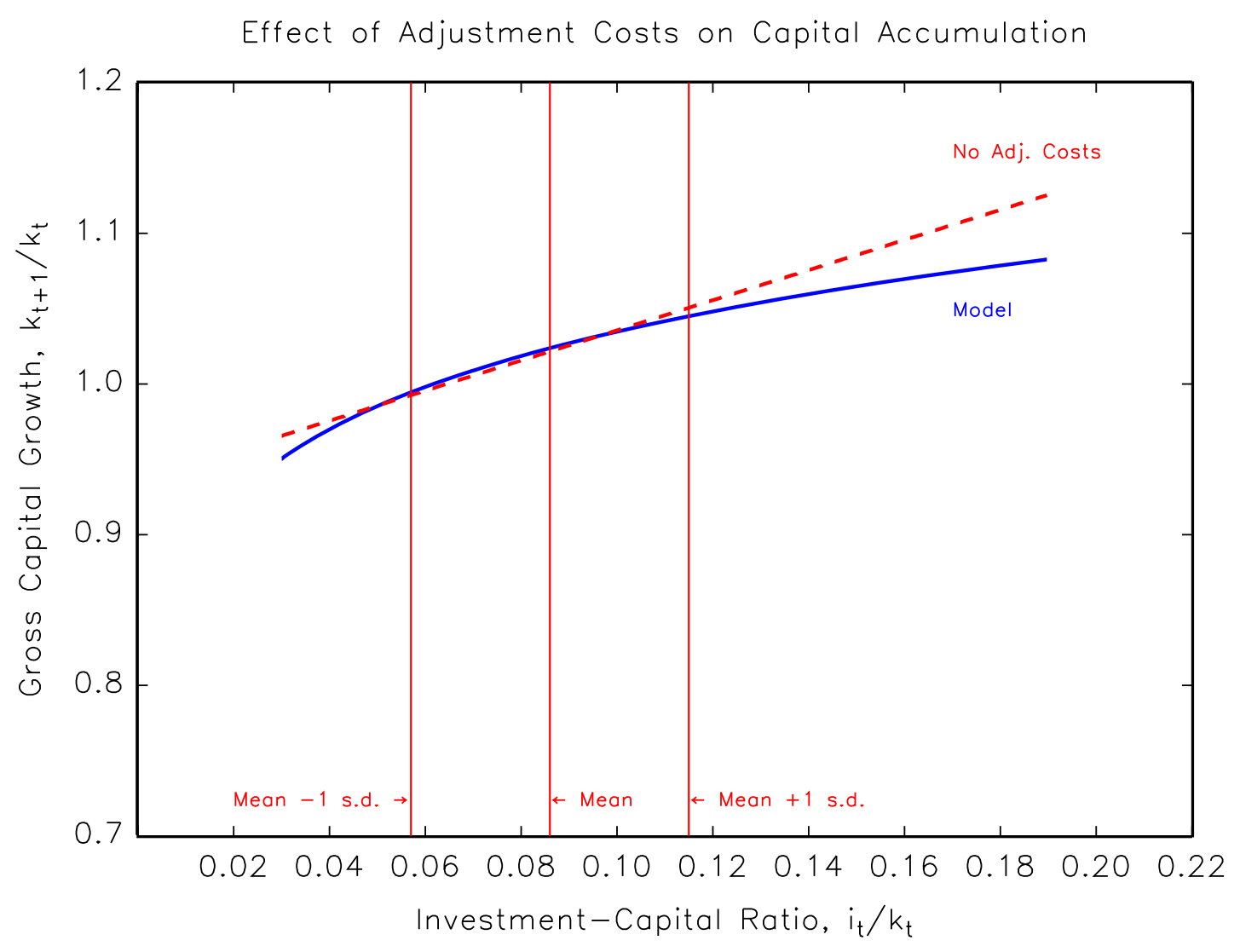

Figure 9: Slope of model relationship declines as $i_{t} / k_{t}$ ratio rises above mean value. 